


\title{
Creativity and Creative Teams
}

\author{
Richard M. Wood, Steven X. S. Bauer", and Craig A. Hunter"
}

\begin{abstract}
ABSTRAC"I
A review of the linkage between knowledge. creativity, and design is presented and related to the best praclices of multidisciplinary design teams. The discussion related $t o$ design and design teams is presented in the context of hoth the complete aerodynamic design community and specifically the work environment at the NASA langley Research (enter. To explore ways to introduce knowledge and creativity into the research and design environment at NASA I angley Research (enter a creative design activity "als execuled within the context of a national product derelopment activity. The stceess of the creative design team actisity gare rise to a need to communicalc the experience in a straightforward and managed approach. As a result the concept of creative potential was formulated and assessed with a survey of a small portion of the acronauties research staff at NASA I angley Research center. The final section of the paper provides recommendations for future creative organizations and work ens ironments.
\end{abstract}

\section{INTROIDUCTION}

To design is to create; which requires knowledge, or to quote Kucheman. "Ideas and concepts come out of the mind, not out of computers or wind tunnels" !

Design: a new concept, model, or artifact with desired function, performance , or end

Create: to bring something new into being

\footnotetext{
$\div$ Senior Research Acrodynamicist. Comiguration Aerolynamics Branch. NASA Langley Research Center. Associate Fellow AlAA

$\rightarrow$ Aerospace Engineer. Configuration Aerodynamics Branch. NASA Langley Research ('enter.
}

('opyright ic 2001 by the American Institute of Acronatices and Astronatutics. Ine. No copyright is asserted in the United States under litle 17. 1.S. Code. The lls. Government has a royalty-free license to exercise all rights under the copyright clamed herein for governmenl purposes. All other rights are reserved by the copyright owner.
In pursuit of reduced cost the acronautics community has increased its reliance upon computational tools for both aerodynamic analysis and design ${ }^{2.3}$. computational based design and decision making also dominate the multi-disciplinary design environment. As this trend continues. the knowledge that is the critical element in design practice could erode as computational tools replace the need for human interaction. resulting in a stagnant design technology landscape. While man! still believe that computational design is the pathway to improsed efliciency and effectiveness in the design environment. others are starting to question the reliance upon computational tools. A portion of the design community believes that it is critical to maintain human involiement and learning in the design and analysis process ${ }^{-t / x}$.

The literature on design shows a wide diversity of methods, concepts. and ideas heing investigated and dereloped' ${ }^{2}$. In general, these concepts fall into two groups. those that are computationally-based such as Multi-Disciplinary Optimization ${ }^{3}$, and those that are knowledge-based such as Decision-Based-Iesign ${ }^{1-}$. The primary assumption of computationally-based design is that a design process can be modeled in the computer to allow the computer to find the optimum design more efficiently than a human can. The assumption behind the computationally-based design is based upon the use of explicit and critical knowledge only, and does not recognize the role of tacit and intuitive knowledge and other human senses and capabilities in the design process.

At the other end of the design spectrum an knowledge-based design methods ${ }^{23}$ in which it is recognized that all knowledge as well as passion is required to find the best design. Knowledge-based design employs tools that allow a designer to utilize their skills, senses, and knowledge in pursuit of a desired outcome. Knowledge-hased design should not be confused with Artificial Intelligence or Expert Systems, because those systems assume that human knowledge and decisions can by fully modeled into a process and computerized. It is unlikely that we will ever be able to totally model the extent of our knowledge. because the extent of it is unknown. 
This paper is designed to follow the discussion presented by the authors in reference 23 . The purpose of this paper is to show the linkage between knowledge. creativity, and design, and to relate these concepts to the best practices of multidisciplinary design teams. The paper will first discuss the environment within the aerodynamic design community. This will be followed by a review of the concepts of design. creativity, and knowledge. A discussion of creative teams and the creative potential concept will follow. The final section of the paper will discuss future creative organizations and work environments.

To assist the reader a listing of definitions is provided after the references.

\section{PROBILM AND SOL.UTION PATHWAY}

\section{Problem}

One of the significant issues facing the engineering community is the failure to recognize that a designer is a unique and highly skilled individual. The distinction between a designer and a person doing design work is vast. The first uses intellect, knowledge, and passion to create, and the latter executes a routine process that re-creates.

In today's environment the issue of cost is the dominate force in design ${ }^{2.3}$. This focus is often at the expense of creativity, innovation, and performance. The primary means to achicving cost reduction has been through the use of computer modeling of design processes ${ }^{2+}$. While computers ane an important tool to the engineering design community, it is a mistake to view them as the primary tool of design. In the quest to be viewed as being on the forefront of technology, may be looking to automate processes, and computerize the capabilities and skills of engineers ${ }^{4,11.17}$. In developing these engineering information models. design knowledge is frozen at a given time and new knowledge generated some time in the future will not be utilized. The concern is that the creative and innovative practices of the past will be replaced with routine processes. Another possible byproduct of this trend is that there will be a severe lack of "understanding" of final design performance and "judgement" by those doing design to interpret the results. If this occurs costly redesign during the development and production activities could result.
The final issue of concem is reflected in the designdevelopment time line as shown in figure 1 . The figure shows that the opportunities to impact performance or cost of a design are heavily weighted toward the conceptual design phase where the design activity is typically guided by first order effects and simple models ${ }^{3+1 *}$. Very often only a fraction of the available knowledge (Design Input) for the particular design problem is used during this phase of the design. This inverse relationship between knowledge used and the ability to impact the design must be corrected if significant improvements are to be achicved.

\section{Solution Pathways}

If the reader accepts the notion that knowledge-poor design activities are a problem for the acrospace community then it is the authors opinion that the pathway to the solution leads through the concepts of knowledge and creativity. First, it must be recognized that the design activity must be a highly creative endeator if cost is to be minimized and performance maximized. Second. the design activity must be a knowledge-based activity that will provide significant intellectual freedom. And third, designers and not the design process are the critical element in design". These ideas are graphically depicted in figure 2. in which the change in the design output (performance and cost) as a result of increasing the knowledge and creativity, in the early phases of design. is shown. By inserting more knowledge and creativity into design. greater cost and performance benefits will be achieved earlier in the design. The result is a better, faster, and cheaper design.

An extension of these ideas leads to the concept of creative design. where a creative design is delined to be: a new concept based upon a non-obvious solution to a difficult problem. The creative aspect of the design is derived out of inspiration that is driven by a difficult challenge. It is important to note that a creative design requires high degrees of knowledge and inspiration. coupled with a very difficult challenge. This concept is graphically depicted in figure 3 which shows a simple model of a design space defined by three parameters: challenge. knowledge, and inspiration. As shown in the figure a "traditional design" is driven solely by knowledge and challenge and a "creative concept" is produced when 
knowledge and inspiration are used. Also note; "brainstorming" uses inspiration and challenge but does not require extensive use of knowledge. But to achieve a creative design. one must utilize knowledge and inspiration directed towards a difficult challenge.

\section{FROM DATA TO DESSIGN}

1)ata is the foundation of knowledge. Knowledge is the foundation of creativity. (reativity is the foundation of design. These simple statements would lead one to believe that the relationship between data and design is straightforward and thus can easily be modeled. However, a close examination of the transformations of data to knowledge, knowledge to creativity, and creativity to design shows that there is ever increasing complexily involving both explicit as well as implicit assumptions that are made hy the designer. To provide additional insight. a simplistic model of these relationships is depicted in figure 4 . Note that the model consists of a closed loop element entilled "Research" which represents activities that support the development of knowledge. understanding. and judgement. In general, the activities that produce data and information are process driven. whereas knowledge, understanding. and judgement are developed by exercising "best practices".

To define knowledge, as related to engineering, one must also define data and information. The following delinitions are provided:

Data: $\quad$ a group of fact or statistics that have not been assigned meaning.

Information: data that has been assigned meaning.

Knowledge: the sum of what has been perceived and learned that allows for the generation of new information.

\section{Knowledge}

A graphical depiction of the interrelation between data. information, and knowledge is presented in figure 5. The figure shows that data are operated on by knowledge to produce information and a new set of knowledge. This knowledge set is then used in the interaction with new data and new information sets.
Another important aspect of knowledge creation is the four modes of knowledge creation introduced by Nonaka ${ }^{13}$ in 1995. see figure 6. In this model. there are two basic types of knowledge. tacit and explicit. Nonaka states that knowledge is created by the conversion of tacit to both tacit and explicit and from explicit to both tacit and explicit.

The final knowledge concept provided herein is the notion of a "Knowledge Matrix" (figure 7). which is borrowed from the work of Margolis ${ }^{15.25}$ in 1987 on a cognitive model he termed the "Belief Matrix". Margolis states that there is tension between critical and intuitive scruting to a question and the ses $(+)$. no (-), and maybe (o) answers to the critical and intuitive question form nine affective states. For this discussion, the nine affective states of Margolis have been renamed to reflect levels of knowledge awareness. In the "Knowledge Matrix", there are four levels of knowledge awareness: Known Knowledge. linknown Knowledge. Probable Knowledge. and Possible Knowledge. These states reflect the concept that "all" that is possible to be known can be known. For the present discussion Known Knowledge is renamed Knowledge, Inknown Knowledge is renamed Inderstanding. Probable Knowledge is renamed Judgement. and Possible Knowledge is renamed Inspiration. The definitions of Inderstanding. Judgement, and Inspiration are provided below:

Understanding: identification of the significance for cerlain data, information, and knowledge.

Judgement: the selection of a course of action, hased on knowledge and understanding.

Inspiration: the action or power of moving the intellect or emotions to impart knowledge to achieve an end goal.

The important aspect of this concept is that traditional design systems that are computationally based either use only the $(+/ I+$ Knowledge state or all of the $C+$ states. But in a creative design activity Knowledge, Understanding. Judgement, and Inspiration are used (i.e. all aspects of know ledge)

A further review of figure + show that a person's knowledge, understanding, and judgement form the basis for exercising ones creativity. When addressing a particular problem. creativity is driven by inspiration. When a difficult challenge is presented to the designer, creativity drives the solution. 


\section{Design Models}

In contrast to a person doing design, the designer begins a "creative design" challenge by taking an unbounded view of the problem. This first step is critical and may be viewed as designing the design. The act of designing the "creative design" provides context and content but does not constrain or inhibit the activity. The relationship between a "traditional design" space and a "creative design" space is depicted in figure 8 . The creative design space is defined by ever-expanding layers of possible solutions that are based in knowledge, understanding. judgement, and inspiration. These layers allow for the inclusion of unseen solutions to the design challenge. In contrast, the graphic of ligure 8 represents that typical design space as a square box located within the creative design space. The box represents the rigid and restrictive nature of the traditional design activity that does not allow for unknown solutions to be achieved.

The operational characteristics of the traditional design process and creative design practice are shown in figure 9. As one would expect, the true designer usually prefers the creative design practice as depictod on the right side of figure 9. However, politics, resources, and culture attempt to drive the designer to the typical design process as shown on the left. The major differences between the $t w o$ are that the traditional design process is an inside-oul activity, which utilizes only a small section of the design space, whereas the creative design practice is an outside-in activity, which utilizes the full design space.

A Traditional design is initiated by defining a specific goal. constraints, selection of tools, and the development of a rigid design process (see left side of figure 9). The traditional design activity then cycles within the framework of the pre-selected design process to achieve a solution.

The creative design activity. shown on the right side of figure 9 , relies upon the challenge and inspiration to drive the development of possible solutions while basing all decisions on knowledge, understanding, and judgement. The creative design practice does not tie itself to a goal or constraints, but instead uses the goal and constraints to define the challenge. The creative design practice does not tie itself to specific tools or processes, but relies upon knowledge, understanding. and judgement to explore solution pathways and candidate designs.

\section{RECENT EXPERIENCES}

The previous sections of the paper have addressed the concepts of design, creativity, and knowledge. This section of the paper will provide an aerodynamicist's view of these concepts and relate them to present design activities at NASA I angley Research Center (LaRC).

As mentioned previously, there has been a significant growth in the use of computers in the design of aircraft, and consequently, there has also been an equally dramatic reduction in the knowledge and creativity used in aircraft design. The changes have been significant. It may be argued that we are about to realize the 1987 prediction ${ }^{26}$

"... what I see in the year 2020. there will be no wind tumels .... we would be at the point where airplanes could be designed by rather low-paid technicians."

Dr. Doug Divoyer

At this time, the aircraft design environment is focused on computational efficiency as a means to reduce cost. And because of the change in the design environment, aerodynamicists have a roduced role. If this trend continues large amounts of design potential may be lost by not including the designers knowledge and creativity into the conceptual design activity.

One reason for these trends in design has been a noticeable transition in the work product at NASA IaRC. This is especially evident in the field of Acronautics. As depicted in figure 10, there has been a transition from a problem-focused research organization into a product-development organization. Mapping the work prior to 1990 into the technology development template (left side of figure 10) shows that the work covered the areas of Science. Engineering, and Technology Design. However a mapping of post 1990 work shows that the areas of Science, Engineering. Technology Design, Marketing, and Service are now included. While on the surface and when viewed in isolation this might not appear to be a significant issue. However, when one takes into account that over the same period of time the budget and staffing have undergone significant reductions serious concerns are raised. if only Aeronautics is considered, the reductions, as a percent of 1990 levels, are much greater. 


\section{Creative Design Demonstration Activity}

A team of researchers at NASA I angley Research Center have recently completed a design activity focused on demonstrating new work practices and changes to the present work environment which an more conducive to a creative research culture. The design activity explored ways to introduce knowledge and creativity into the research and design environment at this center, within the context of a national product development activity. The following discussion will briefly review the elements of this activity. however specific details of the activity will not be presented due to the sensitive nature of the work. Note, a creative design requires inspiration. creativity, and knowledge to be present. A description of those aspects of this particular activity are described below:

The inspiration for the subject activity was threefold: 1) to remind us of the power of the creative process. 2) to encourage change in the current research environment. and 3) the technical challenge did not have an obvious solution. Without the third inspiration element the activity would not have eccurred. In fact, the technical challenge served as the vehicle that carried the first wo inspiration elements.

The lechnical challenge facing the creative design team were:

- Improse performance a minimum of $20 \%$ in several areas.

- Target design was a new product within the detailed design/development phase.

- Team had a three month design window.

- Solution required the development of new science. lechnology, and concepts.

To address this challenge, a creatice design team was formed that was composed of individuals with appropriate levels of knowledge and skills and with a strong desire to actively participate. The first team activity was to develop a set of team rules that were clear. concise, unambiguous, and yet flexible to allow the team to focus on results and not a process. The rules selected are listed below:

- This is a DESICN AcTIVITY!

- Minimize/climinale reviews

- Minimize/eliminate oversight

- Dedicated discussion space.

- Virtual work environment.

- Daily face-to-face design activity.

- Use "Creative Team" model.

- Enforce the "Sunshine Policy"
Fach of the listed rules contributed equally to the success of the team. and all are self descriptive with the exceptions of "Creative Team" and "Sunshine Policy" which are described below.

In this case a "Creative leam" is defined as group of individuals with a shared inspiration directed towards a difficult challenge, who work in a shared environment governed by tacil and explicit knowledge based criteria as well as the rules listed above. A more detailed discussion of this concept will be presented later in the paper.

The "Sunshine Policy" requires that all work. decisions, results, communications. etc. be open and available in real time to all team members.

The team achieved success in all aspects of their work. The team operated for a 3 month period utilizing less than 2 work years of effort and satisfied all technical objectives within the resources allocated. All of the expectations of both the People Managing Work (PMWs) at NASA laRC as well as the customer were exceded by the team. In addition, the team was able to deliver new science, technologies. concepts, and innorations to the aterospace community.

As a result of this demonstration activity. several hest practices have been identilied that should help other creative design activities. These best practices are listed below:

- People Doing Work (PIDWs) must lead

- PIDS must want to actively and enthusiastically participate

- Use the "Creative Team" model

- Enforce the "Sunshine Policy"

- Eliminate external (management) reviews during the design period

- Detailed project plans not required for success

- Management (PMW) function is to provide all necessary resources

- Ise Clear, Concise. Consistent. and Challenging $\left(\mathrm{C}^{+}\right)$goals 


\section{Creative Teams}

Perhaps the most difficult issue faced by the team was the creation of the optimum work environment. In pursuit of this matter the activity considered a varicty of models as depicted in figure 11. The figure show three types of possible teams: Bureaucratic, Hicrarchical, and Creative. The Bureaucratic team is formed by the organization and exists as an element of the organization. This team is recognized as being in competition with other elements of the organization and must operate within the organizational policies and culture. The Hierarchical team is formed by the participating elements of the organization to perform a task of mutual benefit. This leam is supported as long as it is recognized as adding value to the individual elements of the organization. Those who have a shared inspiration and are committed to achicving success form the Creative team. The Creative team operates within the organization environment; however, the Creative team is not one that is typically supported by an organization. The characteristics of a Creative team are increased communications, productivity, and reduced complexity and cost compared to the other two teams. A more detailed description of the "('reative Team" model is presented in figure 12 .

The ability to creale the preferred environment requires the recognition that knowledge is the most valued commodity and that creativity and innovation are critical. If these three characteristics are present then a team can achieve success.

\section{CREATIVE POTENTIAL MODEI.}

The success of the creative design team activity gave rise to a desire by the authors to communicate this experience in a straightforward and managed approach. The hope is that through this effort the scientific and creative research and technology development community will benefit.

A review of the literature on creativity and teaming shows many studies have been conducted on teaming and creativity and that simplistic models have been created $^{27.3 \%}$. However there was not a model specifically directed towards research organizations or a model that provided an explicit representation of creativity. It became apparent that the community may henefit from such a model if it were shown to be a useful representation. As a result, the concept of creatice potential was formulated and assessed with a survey of a small portion of the aeronautics research staff at NASA Langley Research Center. A summary of these results are presented below.

In order to mature the creative potential concept, a hypothesis was developed and modeled. Data were obtained to evaluate the hypothesis that was then updated and revised. The hypothesis is as follows:

The hypothesis:

- All people have the potential to be creative

- A person's creative potential can be both nurtured and destroyed by the environment and the type of work.

- The creative potential of a research scientist or engineer in their ficld of study is primarily a function of an individual's knowledge.

- The knowledge of an individual in a topic area is a function of the number of measurable contributions in the topic area and the number of significant activities execuled by that person.

- An organization's creative potential is a function of the creative potential of the people in the organization, the work environment, and the ratio of people managing work (PMWs) to people doing work (PDWs).

- A person's creative contribution is a function of their own creative potential and the willingness of the organization to recognize and facilitate the use of their creative output.

- An organization's creative contribution is a function of the organizations creative potential and the willingness of the organization to accept failure.

The above hypothesis was formulated into a variety of sub-parameters, which were then rolled up into the four primary parameters; Personal Creative Potential (PCP). Organizational (reative Potential (OCP), Personal Creative Contribution (PCC), and Organizational Creative Contribution (OCC).

PCP reflects the creative potential of a single PI)W and is defined as a function of a PIDW's background and experiences (knowledge) and work environment as derived from the responses in tables 2 and 3 . respectively. The PCP term is formulated to vary between 0.0 and 1.0 .

The $O C P$ term represent an organizations creative potential and as such is defined by the average PCP of the organization's PDWs, the ratio of PMWs to PIWS, and the organization's work environment. The information for this parameter is contained in 
tables 2, 3, and 4. The OCP term is formulated to vary between 0.0 and 1.0 .

PCC represent the ability of a person to utilize their $P C P$ and produce creative products. The PC $C^{\prime}$ term is primarily a function of $P(P$ and $(C P$ and as such is hased upon the data contained in tables 2, 3, and 4 . The PCC term is formulated to vary between 0.0 and 1.0 .

Finally, $O C^{\circ}$ is a function $O C P$ and the organization's acceptance of risk. The organization's acceptance of risk is based upon the information contained in table 5. The 0 ( ' $C$ kerm is formulated to vary between 0.0 and 1.0 .

For each of these primary parameters a creativity threshold or target value was identilied which defines the probahility that a creative design output will result from the work effort. A preliminary analysis of the primary parameters determined that the creativity threshold values would be 0.75 for $\mathrm{PCP}$ and $\mathrm{C}(\mathrm{P}$. and 0.50 for $P C^{\prime} C$ and $O C^{\prime} C$. The threshold values for $P(P$ and $O(\mathrm{P}$ reflect an overall objective of an organization that embraces creativity and that the majority of the staff should be performing creative work: thus a potential value (i.c.. P(P and $O(P)$ should be much greater than .50. The threshold ialues for PC' ' and $C(C$ reflect the fact that they are a product of $O\left(\mathrm{P}^{\prime}\right.$ and $\mathrm{PC} P$. and thus should be set at a value approximately equal to the product of the threshold values for $P(P$ and $O(P)$ (i.e., 0.75 \& (0.75).

To evaluate the model. data were obtained through a survey of the aeronautics PDW staff at NASA langley Research (enter (laR(). The survey contained 48 questions distributed between four eategories as documented in table 1 . The four survey areas werc; work elements, background and experiences, team experiences, and organizational experiences.

The survey was distributed 10.50 PI)WS who work in aeronautics at NASA I aRC. The individuals that participated in the survey represent the brotal spectrum of acronautics work at this (enter. Included in the 50 PIDWs surveyed were the 10 PIDWs involved in the creative design team activity discussed previously. For the following discussion responses from the creative design team PDWs will be referned to as (D) PDWs and the acronautics PIDW responses, which include the (IDT PIDWs, will be referred to as IaRC PDWs. The survey sample represented a little over $14 \%$ of the aeronautics PDW staff at this center. A total of 34 surveys were returned for analysis of which 8 were from (DI PIDWs. A copy of the survey and statistical information of the responses are presented in tables 2 , 3, 4. and 5 for both the LaRC PDWs and the (DT PI)Ws. Table 2 contains information related to the background and experiences of the respondents $(6$ of the 48 questions), tables 3.4 , and 5 contain information on the remaining +2 questions, and table 6 contains information on the four compuled primary parameters (i.c., PCP, OCP. P(' $C^{\prime}$, and $O C^{\prime} C^{\prime}$.

Analysis of the survey results was performed for both the IaRe PIDW responses and the (I)T PI)W responses in order to show the influence of work style and work environment on the creatise potential model. All of the results are presented in figures 1.3 through 18 .

As mentioned previously. P('P is a function of a person's knowledge and work environment. see figures 1.3 and $1+$ respectively. For this activity. a person's knowledge is measured by the tangible and measurable work products as a function of sears in research. As shown in figure 13. the knowledge elements were: invention disclosures, technical reports, experimental studies. computational studies. and design studies. Results for both the I aR( PI)Ws and the subset of (DT PIDWs are presented for comparison. (Overall, the (I)T PIDWs produced more knowledge products than the I aRC PDWs for a given number of years of work experience.

Presented in figure $1+$ are results obtained for the work environment of a PDW. As was done in figure 13. results are shown for both the IaRC PI)WS and the subset of (DT PI)Ws. The survey questions addressing work environment were in a matris format. in which respondents were asked to distribute their time spent performing creative work. non creative work, creative thinking. learning. lost time mistakes, and overhead for their usual work, leam work, and their view of the ideal work environment. Note. the responses obtained for team work from the (I)T PDWs was with respect to the creative design team while the results obtained from the I aRC PDWs was to represent their typical team experiences. An overview of the results show that the subset of (DT) PDWs spend more lime doing creative work and creative thinking and less time doing non-creative work, learning. Iost time mistakes. and overhead. compared to the overall group of I aRC' PI)Ws. This 
indicates that the CDT PDWs have been able to fashion a work environment that is more conducive to creativity despite being in the same organization as the other PDWs surveyed. A comparison of the I aRC PDWs and CDT PDWs change in percent time between the team results and the ideal results show smaller increments for the CDT PDWs, indicating that the creative team experience more closely matched their preferred work environment.

A comparison (PC $P$ values for the usual. team. and ideal work experiences) of the LaRC PDW and (DT PIDW is shown in figure 15. These results show that the LARC PDW values never achieve the threshold value of 0.75 , even for the ideal case. The results for the CDT PDWS show that the threshold value was reached for both the team and ideal work environments. The failure of either of the usual work environment results to achieve the threshold value is likely due to the large amounts of overhead and noncreative work loads for all PDWs surveyed.

The $O C P$ results are shown in figure 16 . These results are presented in the same formal as that for PCP above. Recall that OCP is a function of the PCP value. ratio of PMWs to PDWs, and the organization's imposed work environment. The formulation of this parameter allows for OCP to exceed PCP: however, that did not occur for these results. An analysis of this parameter for the usual organizational work environment showed that due to the large PMW to PDW ratio of 0.4 (extracted from NASA LaRC 2000 phonebook. I PMW for every 2.5 PDWs), the $O C P$ value was consistently lower than the PCP value. For the team values, the PMW to PDW ratio was set to 0.10 (anecdotal evidence from survey showed that a traditional team consisted of 10 researchers with one lead). For the ideal case. the ratio was set to 0.0025 (in order to minimize the impact of the PMW to PDW ratio, we needed to minimize the ratio, so 1 PMW to 400 PDWs was chosen). A review of the OCP data shows similar trends as that seen for PCP but at a slightly reduced level. Note that only the ideal CDT PDW results achieve the threshold value for creativity.

The next two parameters. PCC and OCC, are used to measure the ability of a creative output to contribute to knowledge growth or technology development. Note, the PCC and $O C C^{\prime}$ values are both a function of OCP and either PCP or organizational risk, respectively and as a result the creativity threshold values for both the PCC and OCC parameters is set at 0.50 . These threshold values reflect the constraining nature of an organization on creativity. As defined, an organization is the executive structure of a business. Creativity requires knowledge and the ability to use that knowledge with emotions to achieve an end goal. Based on these definitions, it is clear that an organization benefits from creativity, however, creativity does not noed an organization to flourish.

A review of both the PCC results. see figure 17. and the $O C C$ results, see figure 18 , show results similar to those seen for $\mathrm{PCP}$ and $O C P$. In general the CDT PDW results are higher than the LaRC PDW results and all show an increasing level moving from the usual work environment to the team work environment and finally to the ideal work environment. Note that none of the $O C^{\prime}\left({ }^{\prime}\right.$ results achieve the threshold value due to the perceived inability of the organization to accept any significant risk as noted in the survey responses.

The survey results obtained support the creativity potential model proposed. Based upon this ven preliminary analysis, it may be concluded that the creative potential model may be a useful tool in assessing and developing creative work environments. however, it is recognized that additional assessments are needed to further reline this model.

\section{FUTURE DIRE(TIONS}

Based upon the observations presented above, it is apparent that for an organization that desires to embrace creativity as an essential element and core value needs to provide the appropriate environment for those elements to exist and flourish. The focus should be to create an environment that facilitates creativity, and knowledge generation, and fosters inspiration. Creativity is an especially important element for a research organization. It must also be recognized that the realities of doing business in a cost driven world dictate that the entire organization can not be allowed to operate on creative principles. But for the success of a research organization at least a portion of the staff must have the freedom to pursue creative solutions to problems and as a result not be overly constrained by the institutional aspects of that organization.

The first step is to implement the creative team environment as described in figure 19. The creative team environment challenges leaders to foster inspiration in order to facilitale creative work dinected 
at a difficult challenge within a shared environment. The creative team is characterized by unconstrained knowledge based communications and knowledge based decisions. The creative team environment does not replace the typical (structured) organization. but clouds the typical organization to facilitate a creative environment (see figure 20 ).

The creation of this environment requires the optimization of management stafing ratio (PMW to PIDW ratio) as shown in figure 21 and the acceptance of a knowledge growth model as shown in figure 22. Both of these changes are required if success is to be achieved.

The creativity potential model is a function of the PMW/PDW ratio. In order to assist the reader in implementing a creatice organization based upon the model. the authors would like to propose the following method. To determine the PMW/PDW ratio for a particular engineering/scientific organization, graph the organizations percent of work. based upon resources expended, against work type that the organizations performs. see blue curse on ligure 21 . The pereent work curve is a representation of the distribution of work type within an organization. Also presented in figure 21 is a representative curce of the PMW/PIDW ratio as a function of the work type for scientific/enginecring organizations, see rol curve. The PMW/PDW ratio curve reflects representative PMW/PIDW values for organizations with work that is characterized by the work type listed. The PMW/PIDW ratio data was obtained from phone conversations of scientific and engineering organizations and laboratories. In the most simplistic analysis the optimum PMW/PIDW is determined by the intersection of the \% Work moment of inertia for an organization and the PMW/PIDW curve, as depicted in the figure. The information presented indicates that if a research organization is focused on creativity it should minimize the PMW/PIDW ratio. If an organization were focused on product development/marketing, then it would typically have a large PMW/PDW ratio.

The second critical activity is the implementation of a knowledge growth mechanism for the organization. Note that this model should be used by each individual, team, organization element. as well as the complete organization. A variation-selection model, discussed in reference 36, that serves this purpose is presented in figure 22. The model shows that there are three critical elements in knowledge growth: (1) introduction of variations, (2) consistent selection practices, and (3) preservation and propagation of the variations.

The introduction of variations is the means in which the seeds of a creative output are laid. The variation inputs must have an unseen/unknown output if they are to be of benefit. The concept of unknown output is critical because a creative output is unknown until it is manifested. The second step is the use of consistent selection practices that are not constrained to rigid processes. but utilize both tacit as well as explicit knowledge. An example would be the stopping point of a wing design. This is based upon: how it looks. how it performs at the design point. how it compares to previous work. and the projection of its performance over the entire flight entelope. The final step is preservation and propagation of the variations in which the data and information are converted to knowledge, understanding. and judgement through dexumentation and sharing mechanisms.

\section{CONCI.UIDINGI REMARKS}

Design is a greatly misunderstood and undenalued practice within the engineering community. It is important to recognize that the design philosophy. not the design process. defines the design space. The design philosophy. which is dereloped by the designer, must not be constrained by known rules. constraints. or by computational tools. It must be recognized that the ability to perform conceptual design must not be contingent upon the ability io obtain a computational solution. The efficiency and accuracy of the conceptual design phase is directly related to the knowledge used. and thus we must focus on including ever-greater amounts of knowledge and creativity into the conceptual design phase.

To address the need for improted design capability the following recommendation are offered:

- Implement the creative team model to facilitate the development of design knowledge. design skills, and design systems.

- Utilize the creative potential model as a means to measure and change the design environment.

- Recognize that design is a knowledge-driven creatice activity, not a computational process. 


\section{REFERENCES}

1. Kucheman, D.: The Aerodynamic Design of Aircraft. Pergamon Press, (Oxford, 1978.

2. Newman, P. A., Hou, G.J.-W. and Taylor III, A. C.: Observations Regarding Use of Advanced ('FD Analysis. Sensitivity Analysis, and Design (odes in MDO. NASA (R-198293. March 1996.

3. Kroo, I., Altus, S., Braun, R.. Gage, P. and Sobieski. I.: Multidisciplinary Optimization Methods for Aircraft Preliminary Design. Fifth AIAA/USAF/NASA/ISSMO Symposium on Multidisciplinary Analysis and Optimization. AIAA 94-4325. September 1994.

4. Meyer, D. D.: Future Integrated Design Process. NASA (P-2143. 1980.

5. Null. ( $\therefore$ H. and Jenkins, J. P.:NASA Virtual Environment Research. Applications and Technology. NASA TM-109682. October 1993.

6. French. M. J.: Conceptual Design for Engineers. The Design Council, 1985.

7. Newsome, S. L.. Spillers, W. R. and Finger. S.: Design Theory '88. Springer-Verlag. 1988.

8. Gero, J. S.: Design Optimization. Volume 1. Academic Press. 1985.

9. Liebowitz., J.: An Introduction 10 Expert Systems. Mitchell Publishing, Inc., 1988.

10. Liebowitz, J.: The Handhook of Applied Expert Systems. CRC Press. 1998.

11. Ferguson, F. S.: Fnginecring and the Minds Fyc.. MIT Press, 1992

12. Suh, N. P.: The Principles of Design. Oxford University Press, 1990.

13. Nonaka. I. And Takeuchi, H.: The Knowledge Creating Company. Oxford University Press, 1995.

14. Robinson, A. G. and Stern, S.: Corporate Creativity. How Innovation and Improvement Actually Happen. Berrett-Koehler Publishers, Inc., 1997.

15. Lichowitz, J. and Wilcox. L. C.: Knowledge Management and Its Integrative Elements. CRC Press, 1997.
16. Carr, C.: The Competitive Power of Constant Creativity. AMACOM, 1997.

17. Kidwell, G. H.: The Workshop on Al Applications to Conceptual Aircralt design. NASA TM-10544.5. 1990.

18. Gonda. M., Fertig. K. W., and Teeter, R. J.: Acrospace Conceptual Vehicle design Using an Intelligent Design and Analysis Environment: Design Sheet. AIAA92-4222. August 1992.

19. Papamichael. K. and Protzen,J-P: 'The Limits of Intelligence in Design. I.BL $-317+2$. 4th International Symposium on System research. Informatics and (ybernetics. August 1993.

20. AGARD. Integraled Airframe Design Technology. AGARD-R-814. October 1996.

21. Slocum, A. H.: Passionate Axiomatic Deterministic Design: An Plea for the Future of Designology. Decision Based Design Workshop located at www.eng.buffalo.edu/Research/DBD/

22. Olds. J. R.: Multidisciplinary Design Techniques Applied to Conceptual Aerospace Vehicle Design. NASA CR- 194109. 1993

23. Wood, R. M. and Baucr, S. X. S.: A Discussion of Knowledge Based Design. AIAA-98-49H. Sept. 2-t. 1998.

24. Bryson, S.: Paradigms for the Shaping of Surfaces in a Virtual Environment. RNR-92-012

25. Margolis. H.: Patterns, Thinking, and Cognition: A Theory of Judgement. (hicago: The University Press, 1987.

26. Mayfield, D.: Turning Flights of Fancy into Reality. The Virginia Pilot and Ledger Star. Hampton Roads Business Weekly. Pg. 16-17 February 2, 1987.

27. Stewart, O.: Aviation: The Creative Ideas. 1966. Kim, S. H.: Essence of Creativity, A Guide to Tackling Difficult Problems. 1990

28. Creativity, Liberating the Unconscious for Breakthrough Insights. 1984.

29. Michalko, M.: Cracking Creativity, The Secrets of Creative Genius. 1998. Ryan, K. D. and Oestrich, D. K.: Driving Fear Out of the Workplace, How to Overcome The Invisible Barriers to Quality, Productivity, and Innovation. 1991. 
30. Mowerey, D. C. and Rosenberg, N.: Paths of Innovation, Technological (hange in $20^{\text {th }}$ Century America. 1998.

31. Mason, W. H.: Applied Aerodynamics Literacy: What Is It Now? What Should It Be? AIAA-91 3313. Sept. 23-25, 1991.

32. Bloom, A: The Closing of the American Mind. Simon and Schuster, New York. 1987.

33. Hirsch, E. D. Jr.: Cultural Literacy: What Every American Should Know. Houghton Mifllin Co. Boston. 1987.

34. Ptroski, H.: Human Frror and the Case History in design. Jour, of Engr. Design. Vol. 2. No. I, 1991. pp. 81-88.

35. (iregory, C. E.: The Management of Intelligence, McGraw-Hill. New York. 1967

36. Vincenti, W. (i.: What Engineers Know and How They Know It, Analytical Studies from Acronautical History: Johns Hopkins Iniversity Press. 1990.

\section{DEFINITIONS}

\section{Communications}

Interchange of thoughts, opinions, or ideas

\section{Complexity}

Composed of confusing interrelated parts

\section{Create}

To bring something new into being.

Requires knowledge and inspiration.

\section{Creative Design}

To bring into being a new concept based upon a nonobvious solution to a difficult problem.

Requires knowledge, inspiration, and a challenge.

\section{Creative Team}

Individuals with a shared Inspiration directed towards a difficult Challenge who work in a shared environment governed by tacit and explicit knowledge based criteria.

\section{Culture}

Validated basic assumptions developed by a given group and taught to new members as the correct way to perceive, think, and feel.

\section{Challenge}

A difficult problem that arouse or stimulate creative effort.

\section{Data}

A group of facts or statistics that have not been assigned meaning.

\section{Design}

A new concept, model, or artifact with desired function, performance, or end.

Requires knowledge and a challenge.

\section{Environment}

Aggregate of all conditions and influences affecting an individual or group.

\section{Epistemology}

The study or a theory of the nature and grounds of knowledge especially with reference to its limits and validily.

\section{Excite}

To increase the activity of a group or individual.

\section{Honesty}

Integrity and straightforwardness in ones conduct. thought, and speech.

\section{Honor}

A fastidious allegiance of the standards of ones profession

\section{Information}

Data that has been assigned meaning.

\section{Innovation}

The act of introducing something new.

\section{Inspiration}

The action or power of moving the intellect or emotions to impart knowledge to achicve an end goal.

\section{Judgment}

The selection of a course of action. based on knowledge and understanding.

\section{Knowledge}

The sum of what has been perceived and learned that allows for the generation of new information from new data.

\section{Leadership}

The art of influencing other people to achieve shared goals.

\section{Learn}

To gain knowledge or understanding.

\section{Management}

The collective hody who conduct, control, and direct an interest. 
Method

An orderly procedure followed to achieve an end.

\section{Model}

A simplified representation of a concept or system in which all critical features are described.

\section{Motivate}

To provide an idea a need or to stimulate an emotion to incite action.

\section{Organization}

The executive structure of a business.

\section{Policies}

General guidelines for making management decisions.

\section{Practice}

The accepted application of knowledge within a professional discipline to achieve an objective.

Principles

Simple and direct statements of basic beliefs.

\section{Procedures}

Instructions defined by management for performing a sequence of actions.

\section{Problem}

A question proposed for solution.

Productivity

Effective in bringing forth originative and creative action

\section{Process}

A series of specific actions or operations producing a known end state.

\section{Research}

Critical and exhaustive investigation aimed at developing new understanding through the acquisition of new knowledge.

\section{Results}

Something obtained by investigation.

Team

People who are committed to solving a shared problem.

Technology

A capability given by the practical application of knowledge.

\section{Understanding}

Identification of the significance for certain data, information, and knowledge.

Values

Basic convictions that a specific mode of conduct or end-state of existence is preferable to an opposite mode of conduct or end-state existence.

\section{Virtual Teams}

Teams whose primarily means of interaction is electronic.

Work

Exertion of faculties to accomplish something to solve a problem.

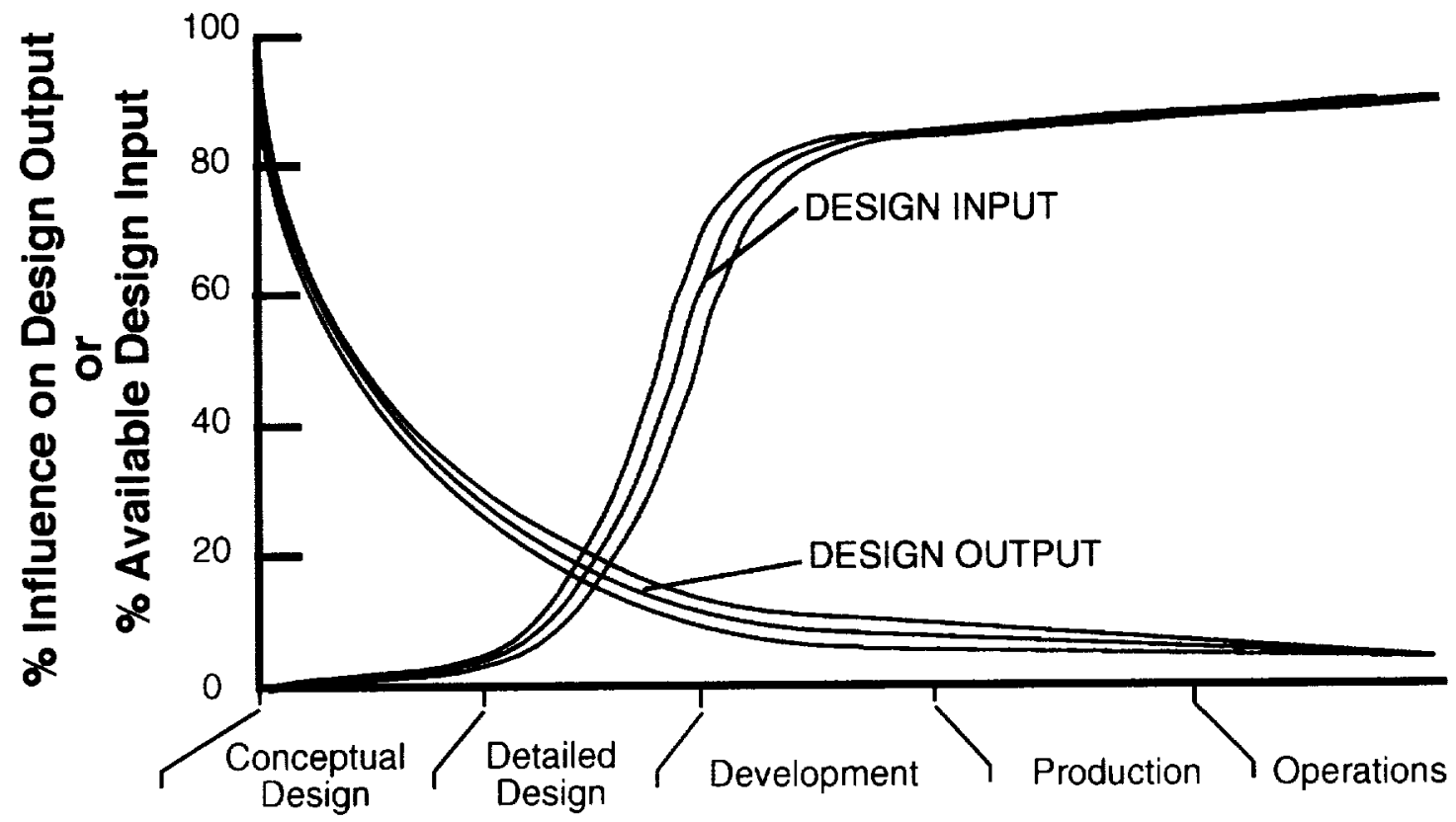

Time Line

Figure 1. Design history model. 


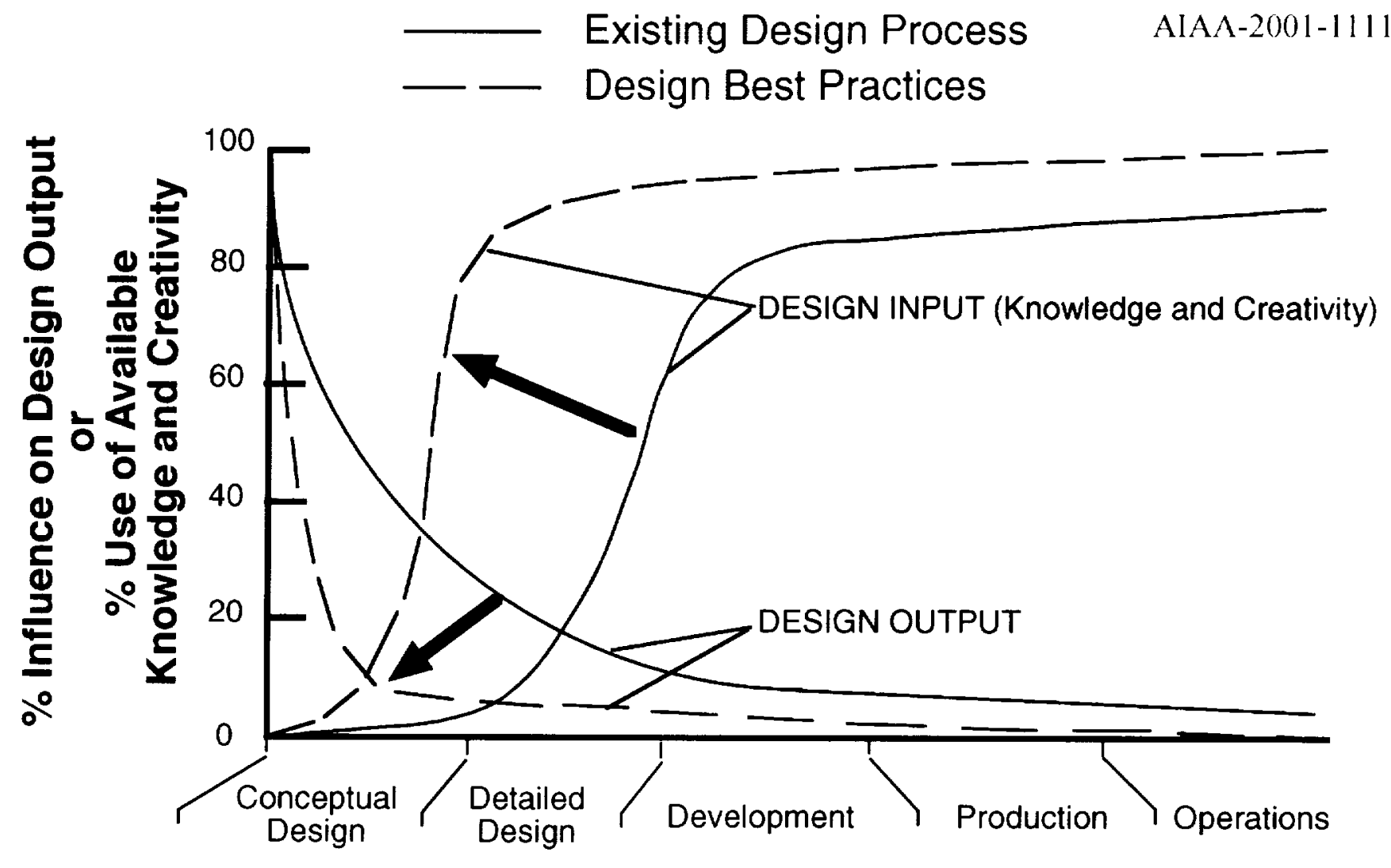

Time Line

Figure 2. Revised design history model.

A Creative Design is a new concept based upon a nonobvious solution to a difficult problem.

A Creative Design requires knowledge, inspiration, and a challenge.

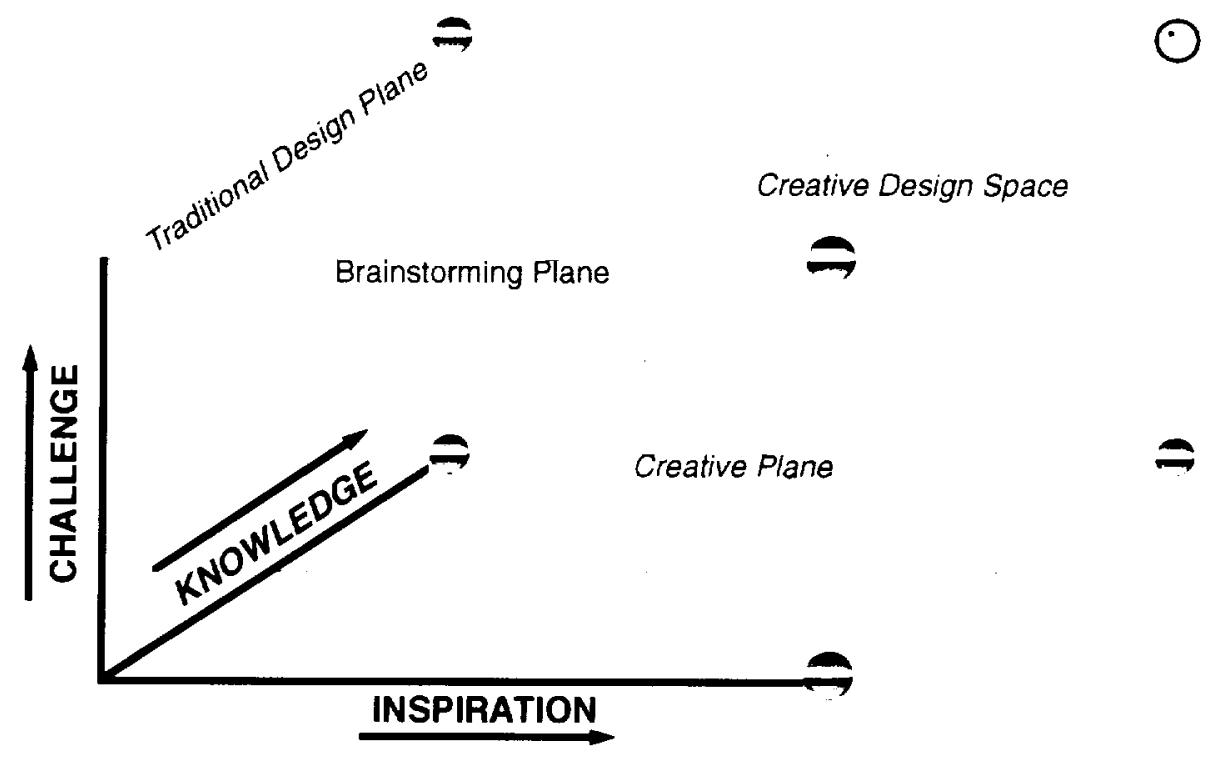

Figure 3. Design space model for creative design. 


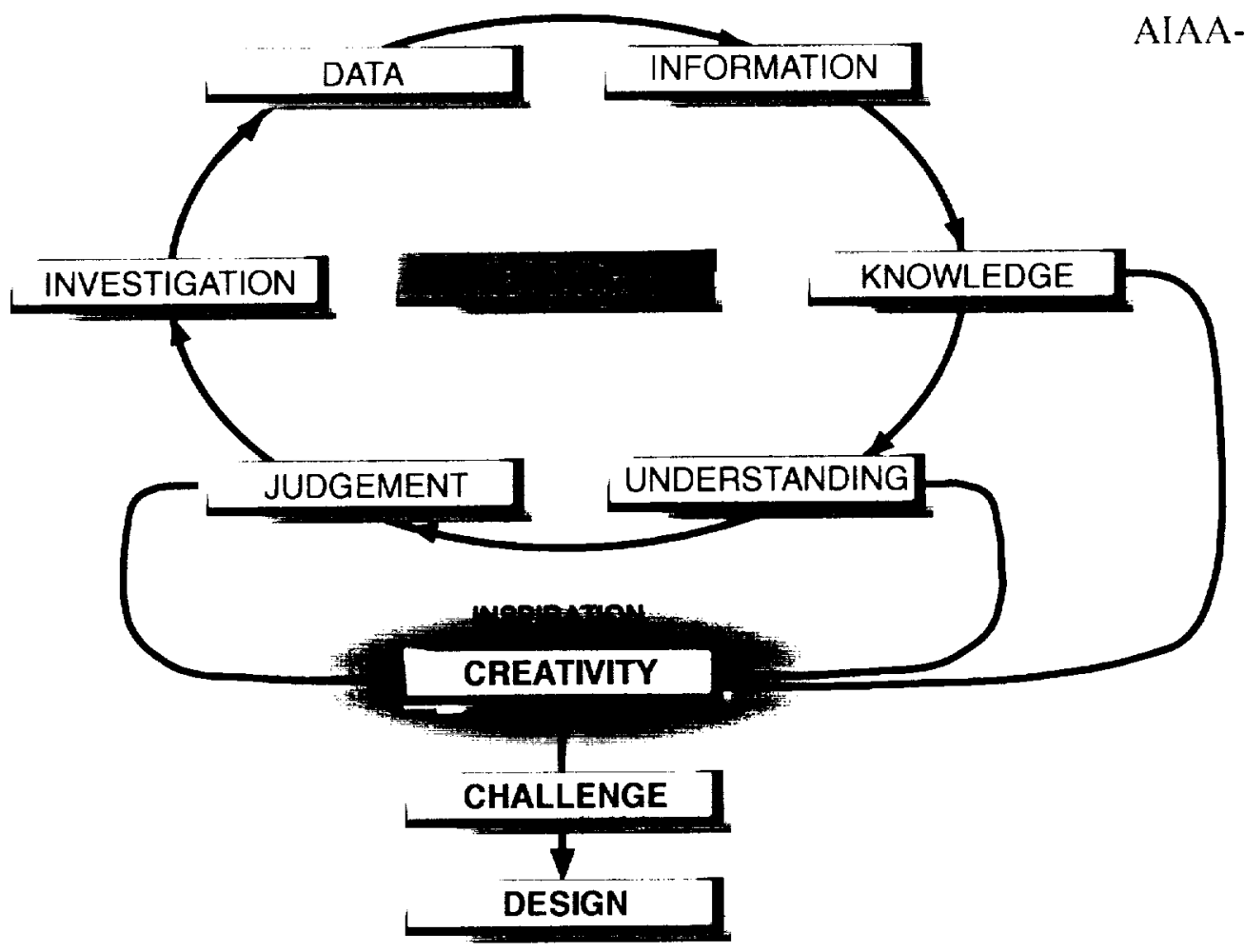

Figure 4. Data to design model.

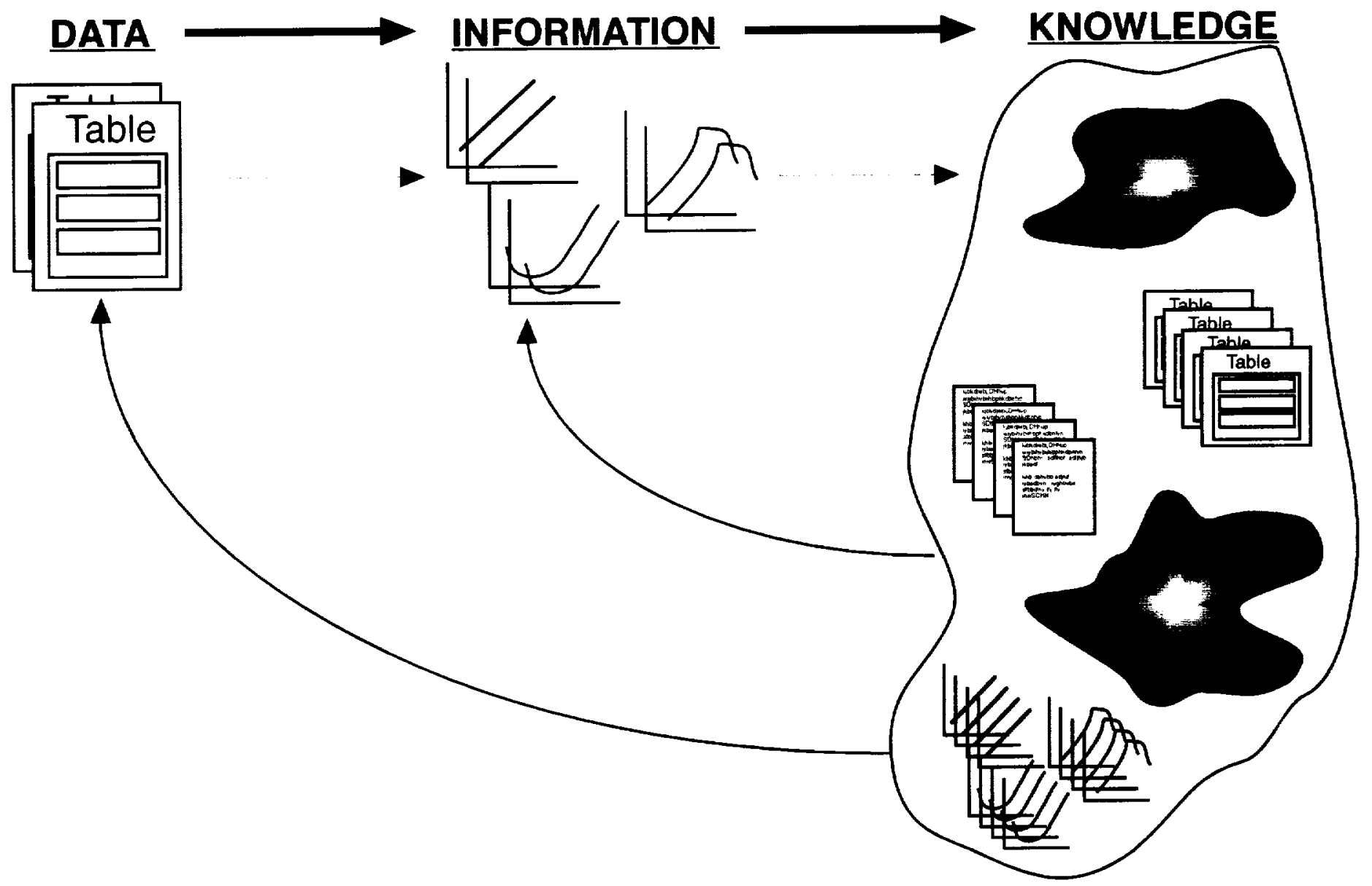

Figure 5. Data to knowledge transition model. 
Tacit - implied but not expressed, subjective

Explicit - clearly developed meaning, objective

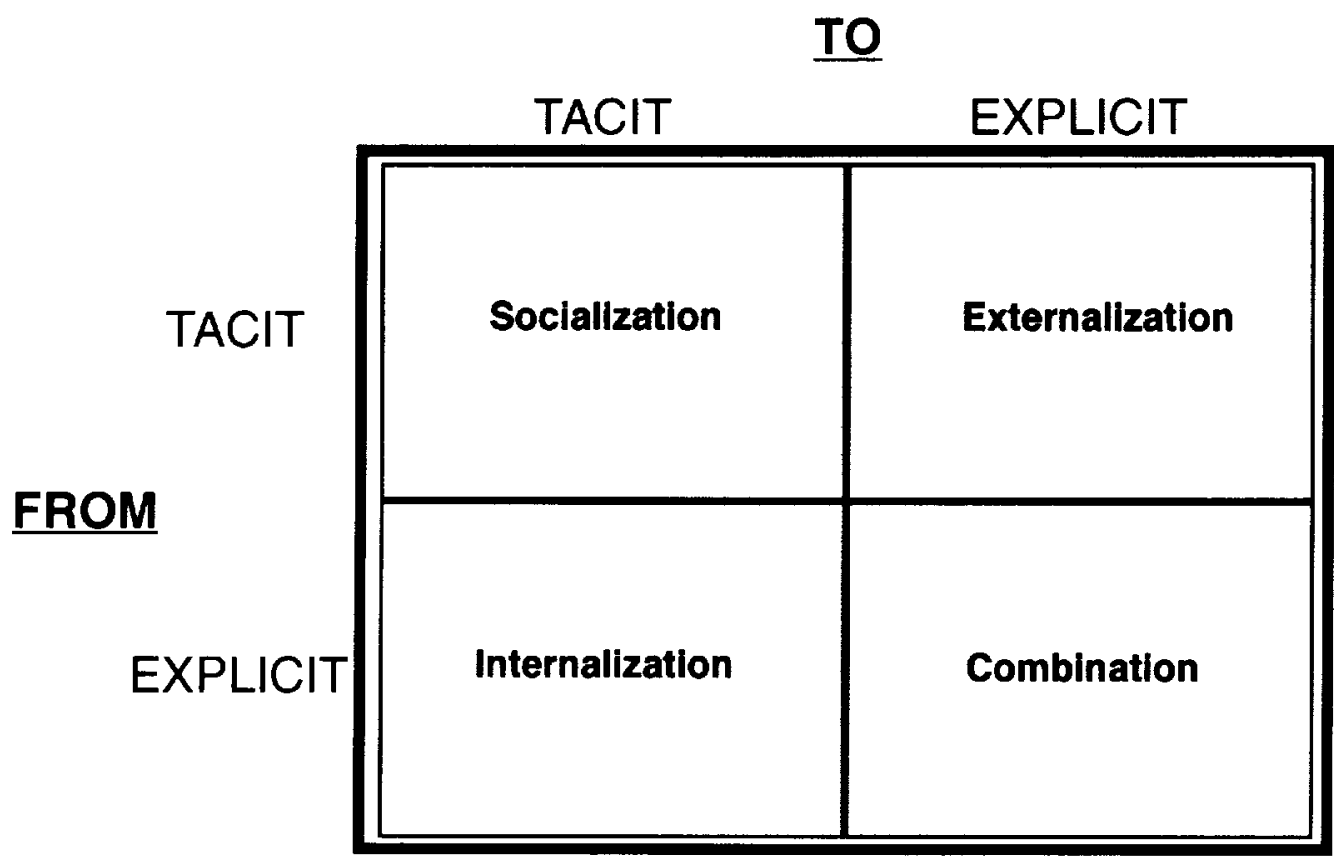

Figure 6. Knowledge creation model.

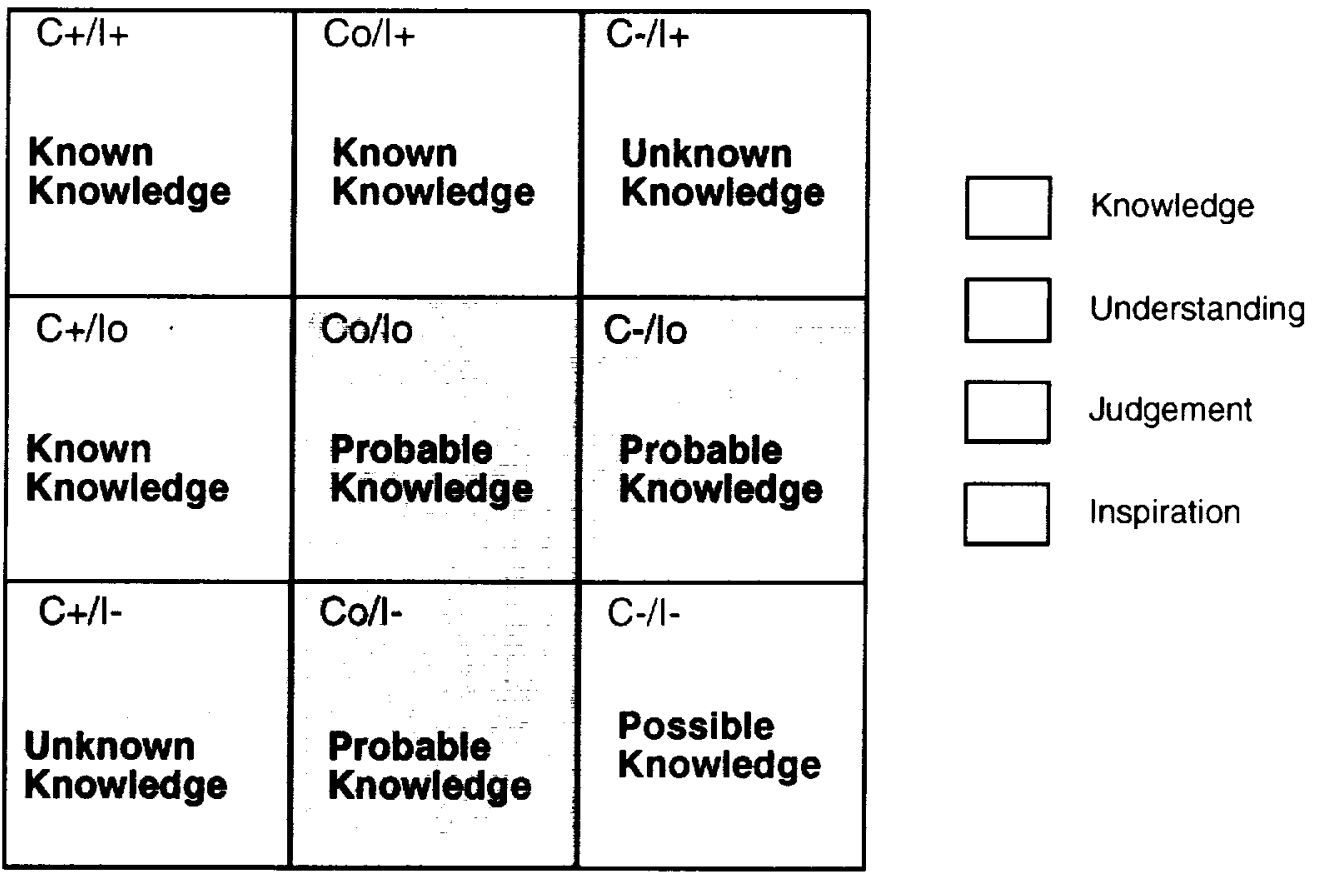

\begin{tabular}{|l|l|l|l|}
\cline { 2 - 4 } \multicolumn{1}{c|}{} & YES & MAYBE & NO \\
\hline Critical $(C)$ Criterion = Do results look convincing/valid & C+ & Co & C- \\
\hline Intuitive (I) Criterion = Do results look/feel right & $\mathrm{I}+$ & 10 & $\mathrm{I}-$ \\
\hline
\end{tabular}

Figure 7. Knowledge matrix. 


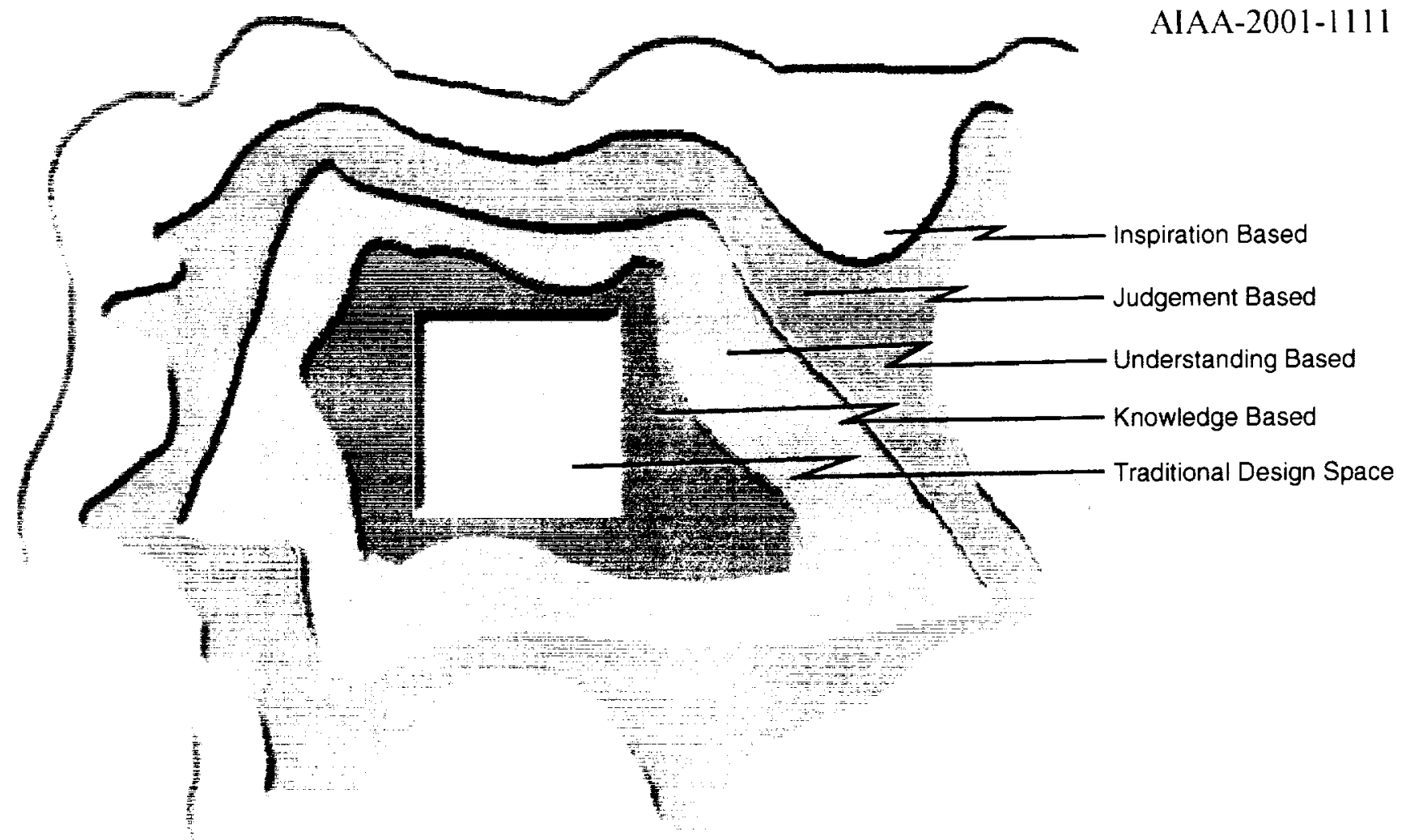

Figure 8. Creative design space model.

Traditional Design Process

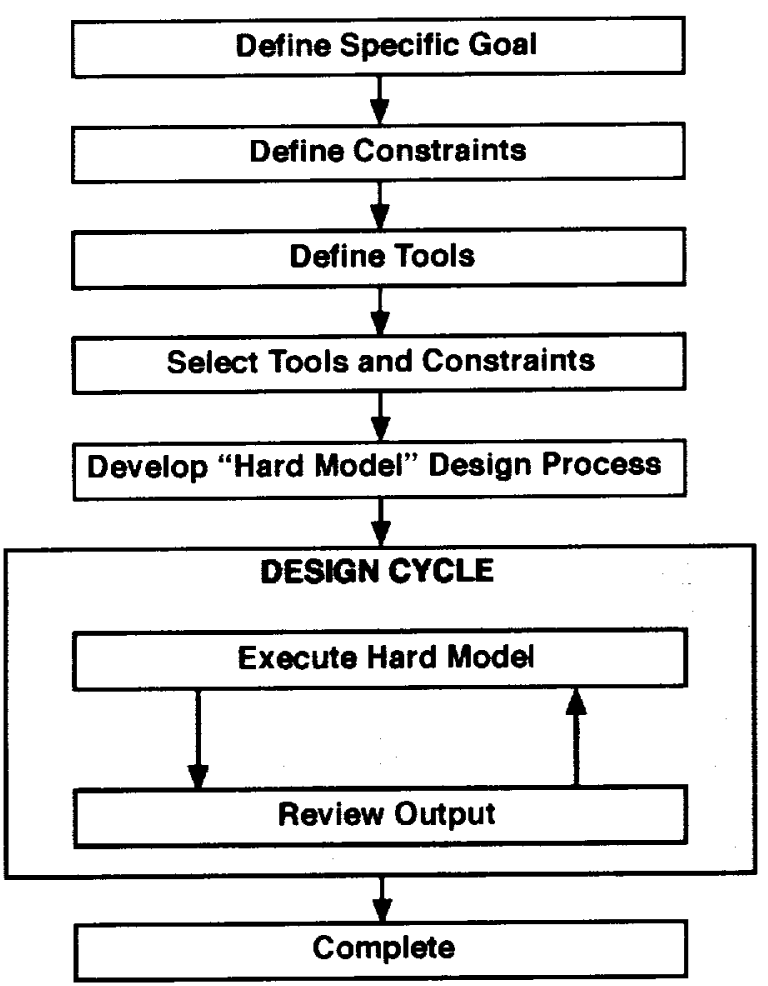

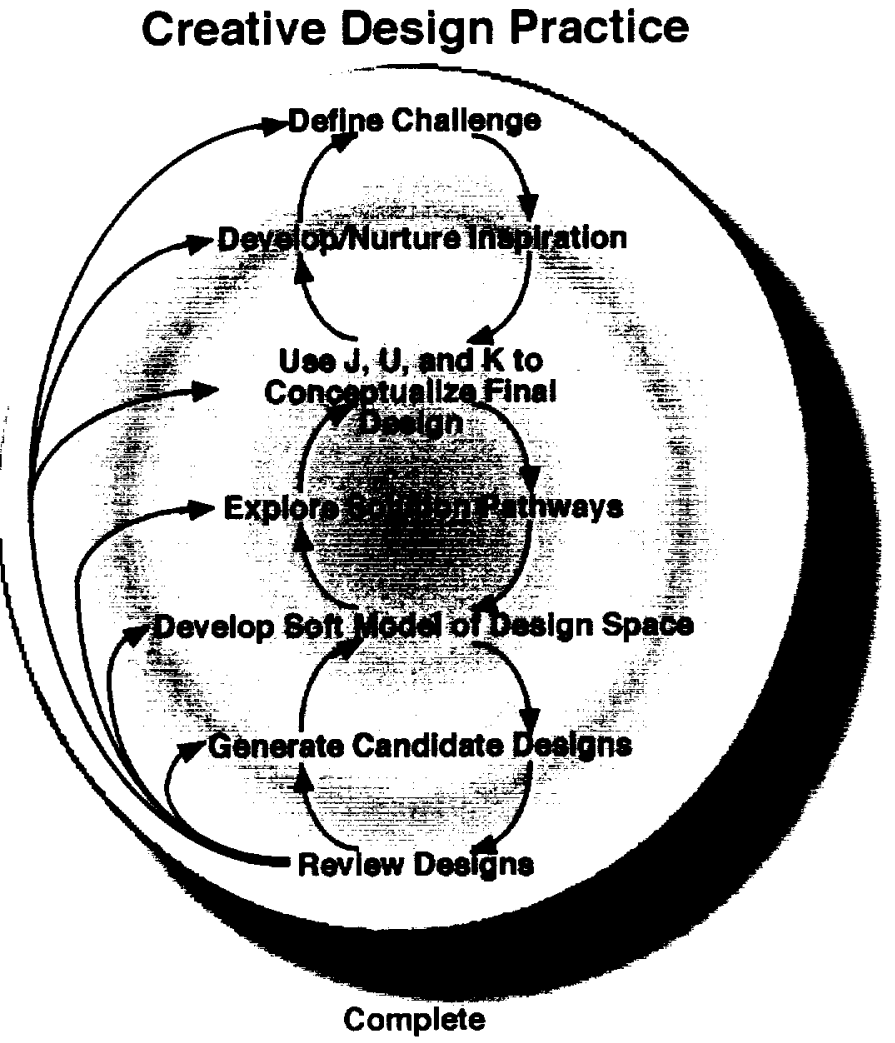

Figure 9. Traditional design process and creative design practice models. 


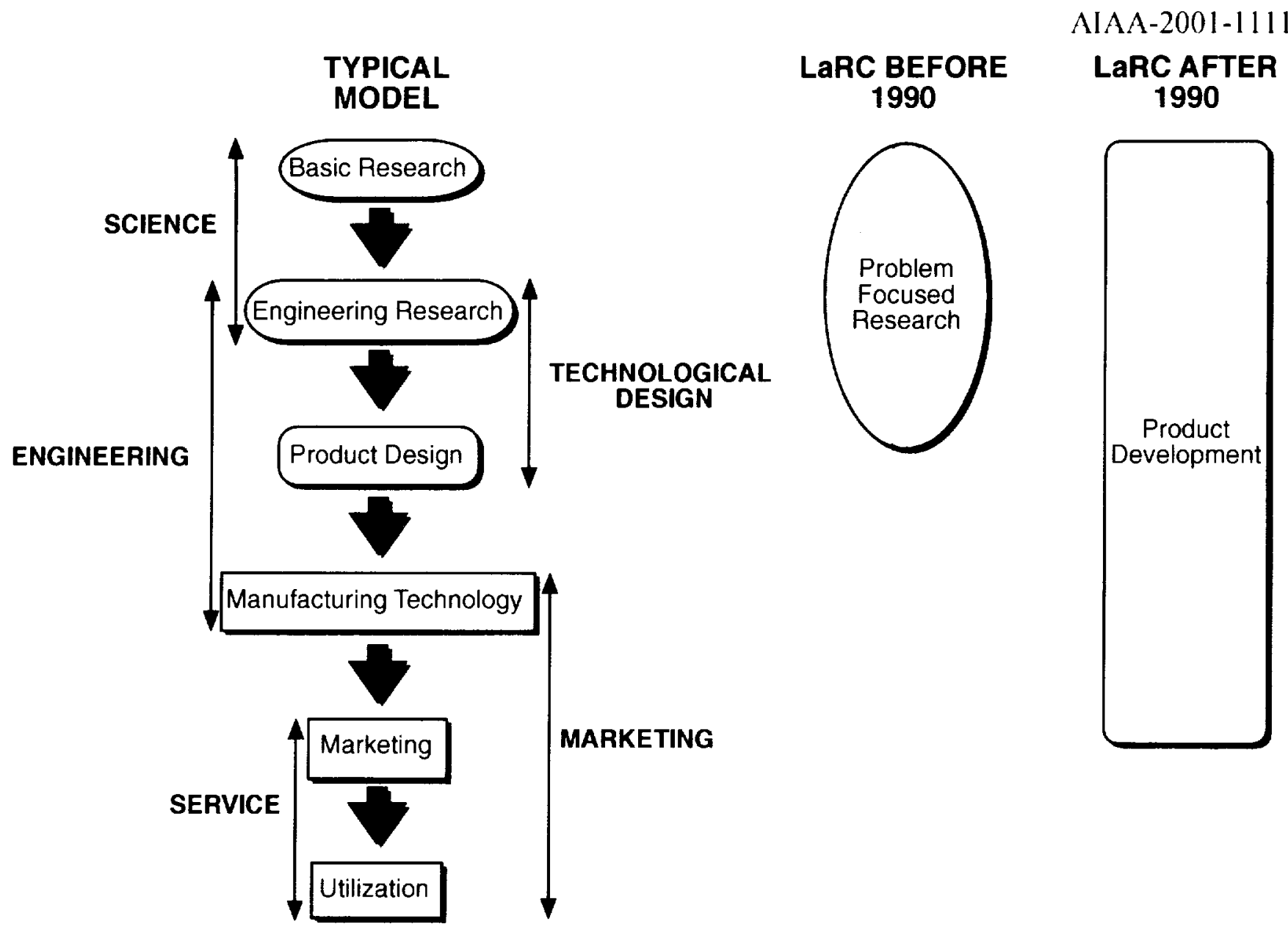

Figure 10. technology development model.

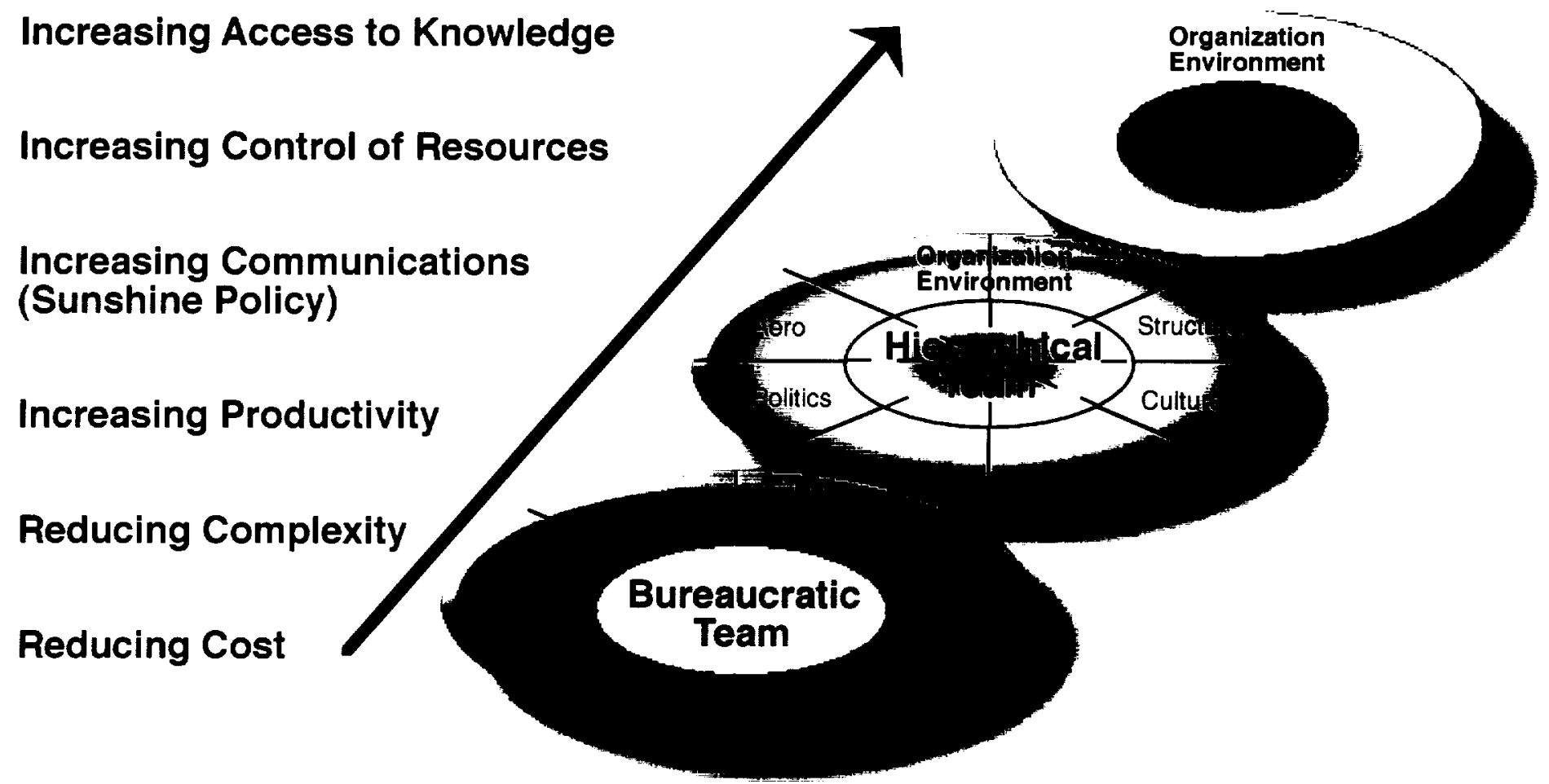

Figure 11. Team types. 
Creative Team: Individuals with a shared Inspiration directed towards a difficult Challenge who work in a shared environment governed by the criteria listed below.

- Only accept work with Clear, Concise, Consistent, and Challenging $\left(C^{4}\right)$ goals. - Minimize/Eliminate oversight.

- Only Knowledge Based decisions.

- Minimize/Eliminate planning.

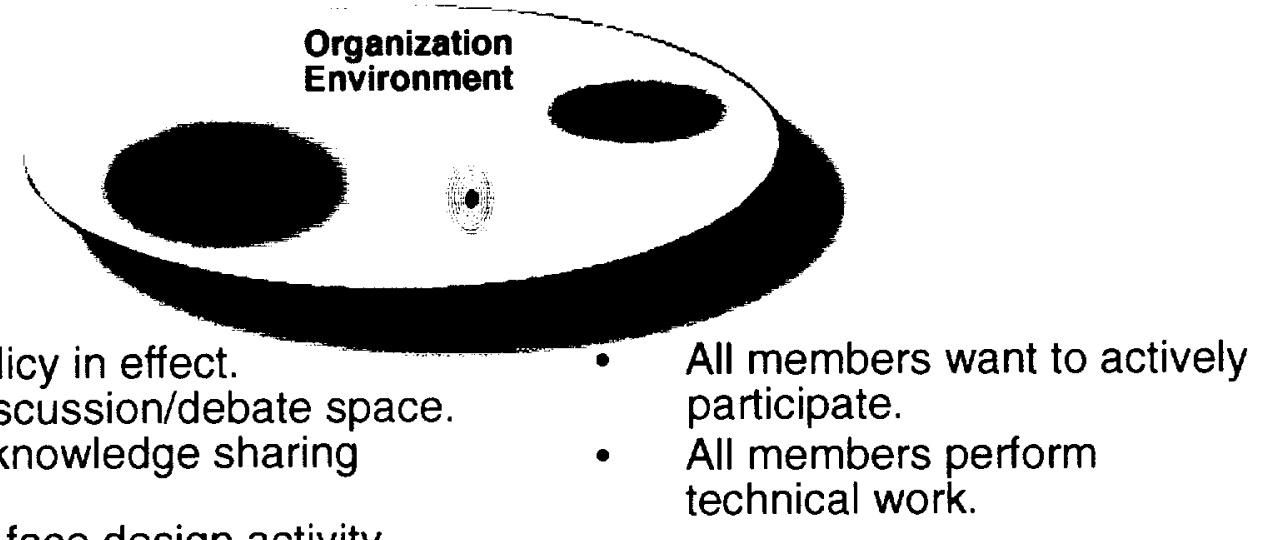

- Sunshine Policy in effect.

- Dedicated discussion/debate space.

- Virtual work/knowledge sharing environment.

- Daily face-to-face design activity.

- All resources provided at start.

Figure 12. Creative team model.

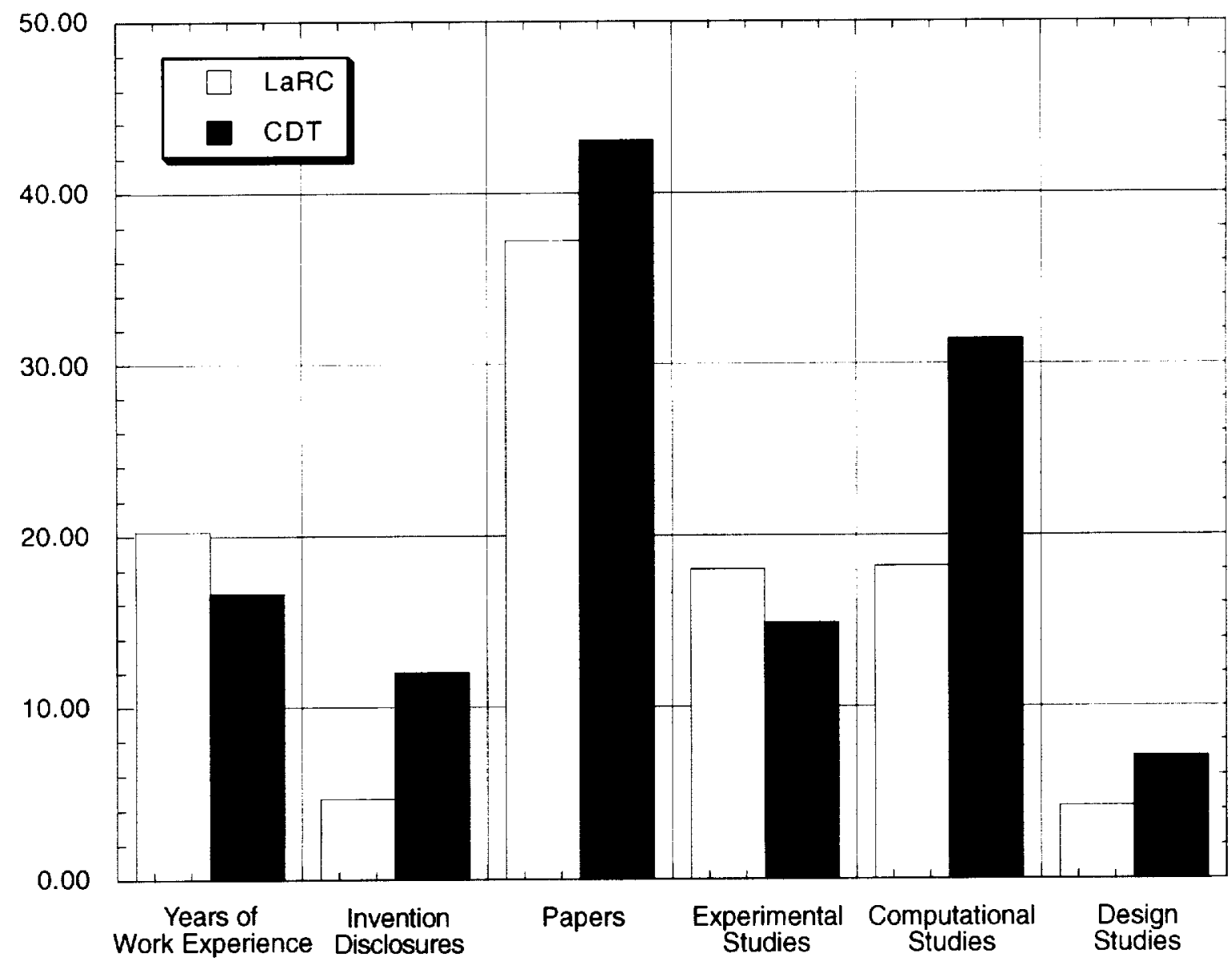

Figure 13. Background and expereince survey results. 


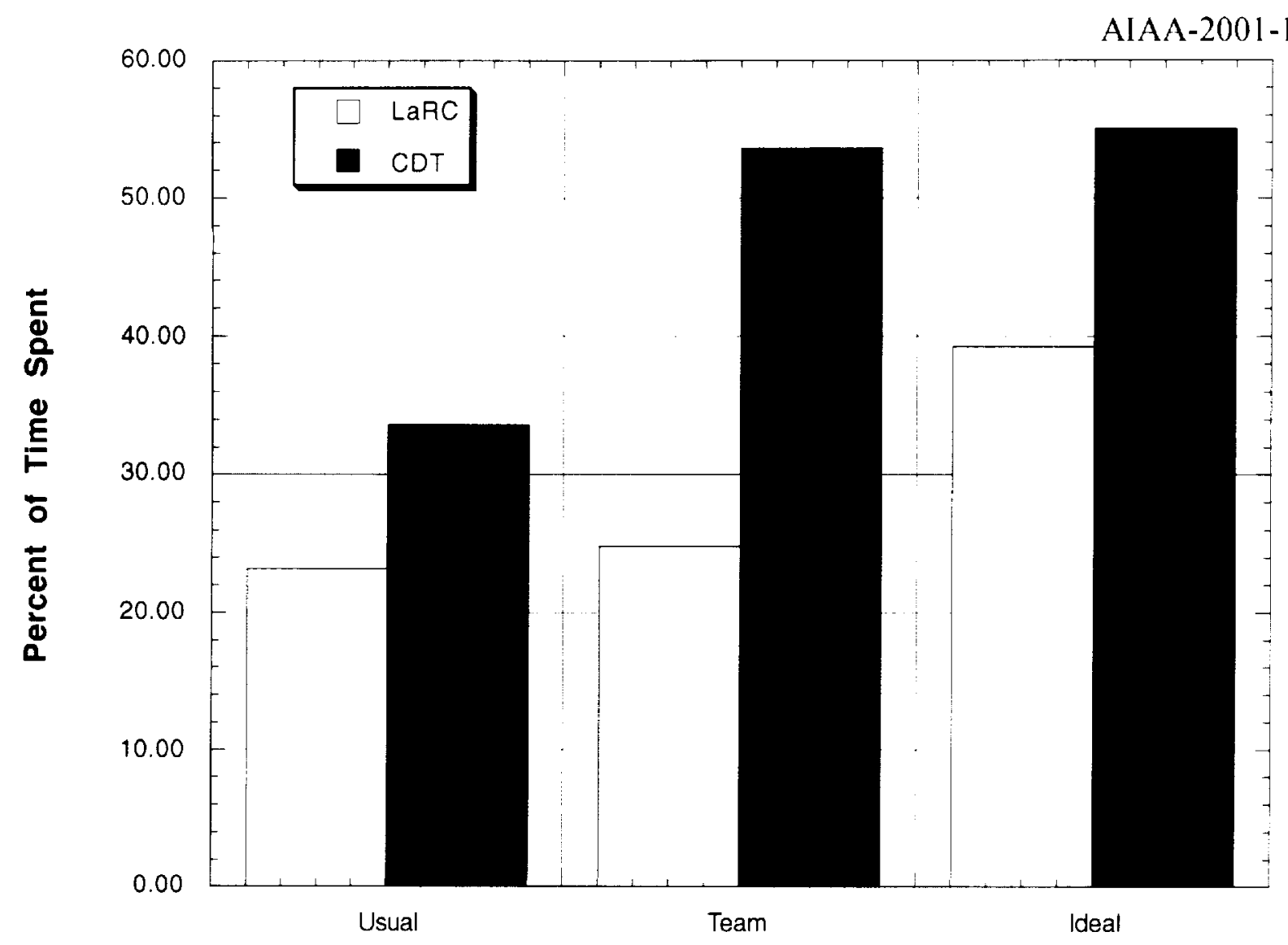

(a) Creative Work

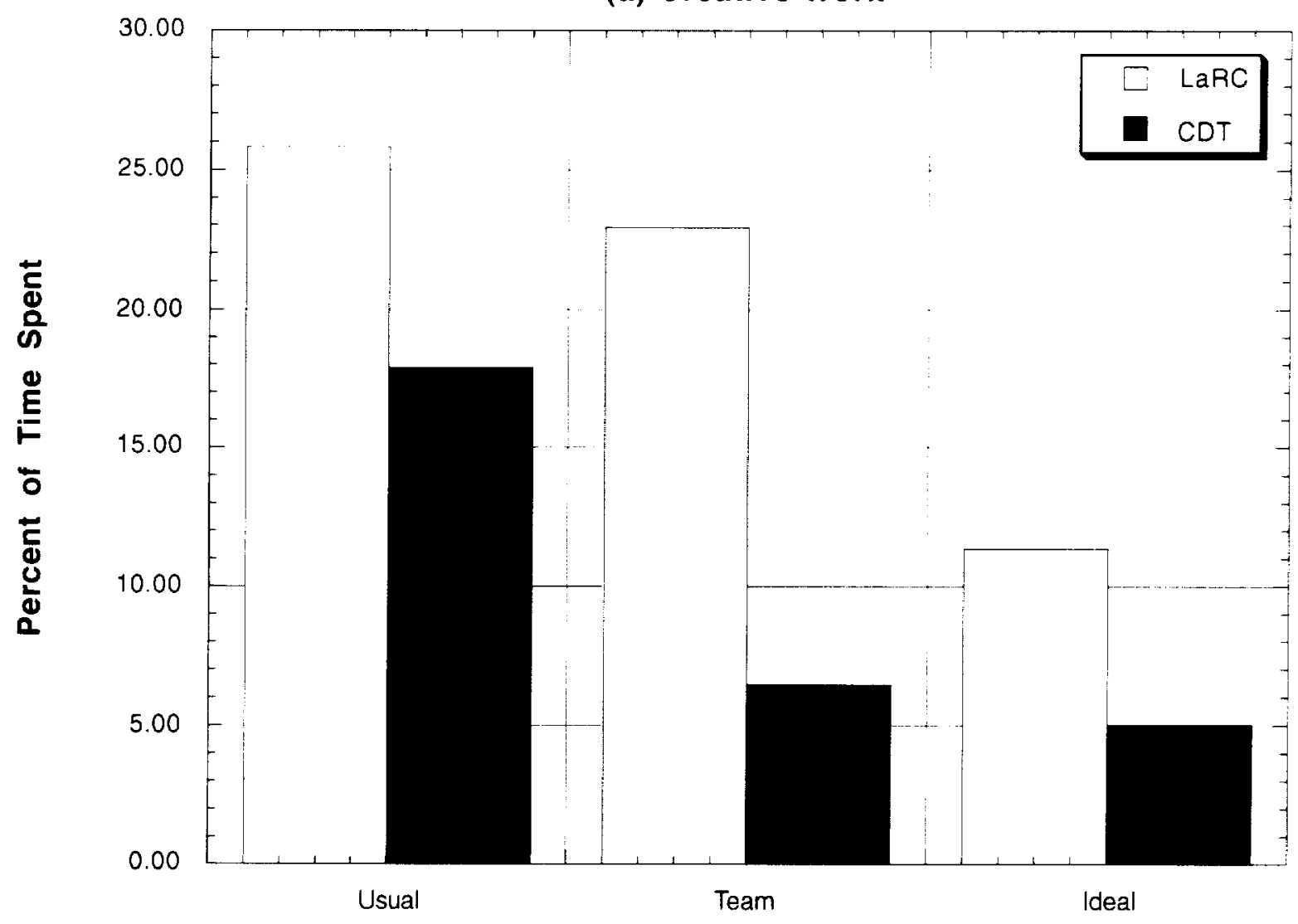

(b) Non-Creative Work

Figure 14. Work elements survey results. 


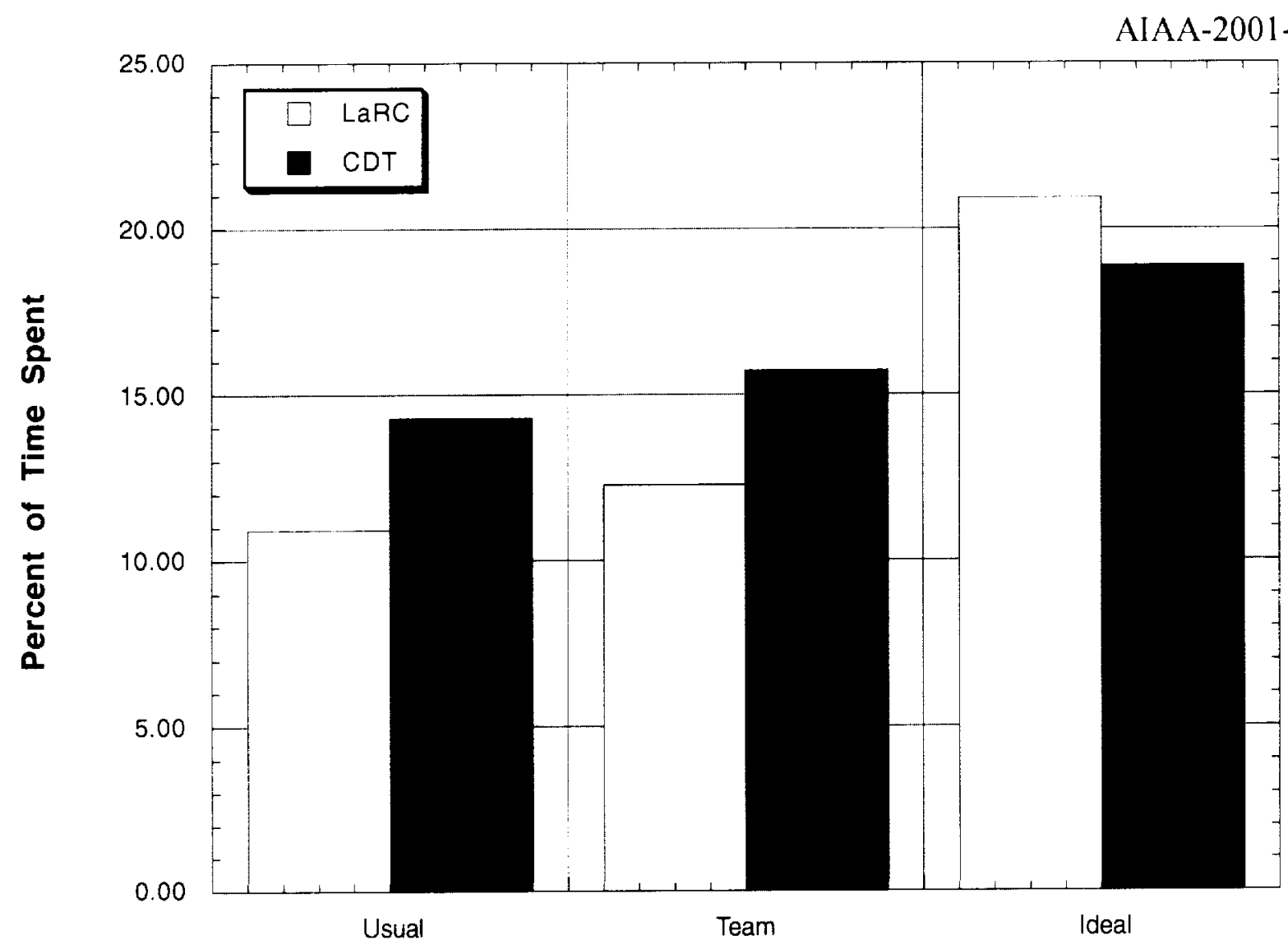

(c) Creative Thinking

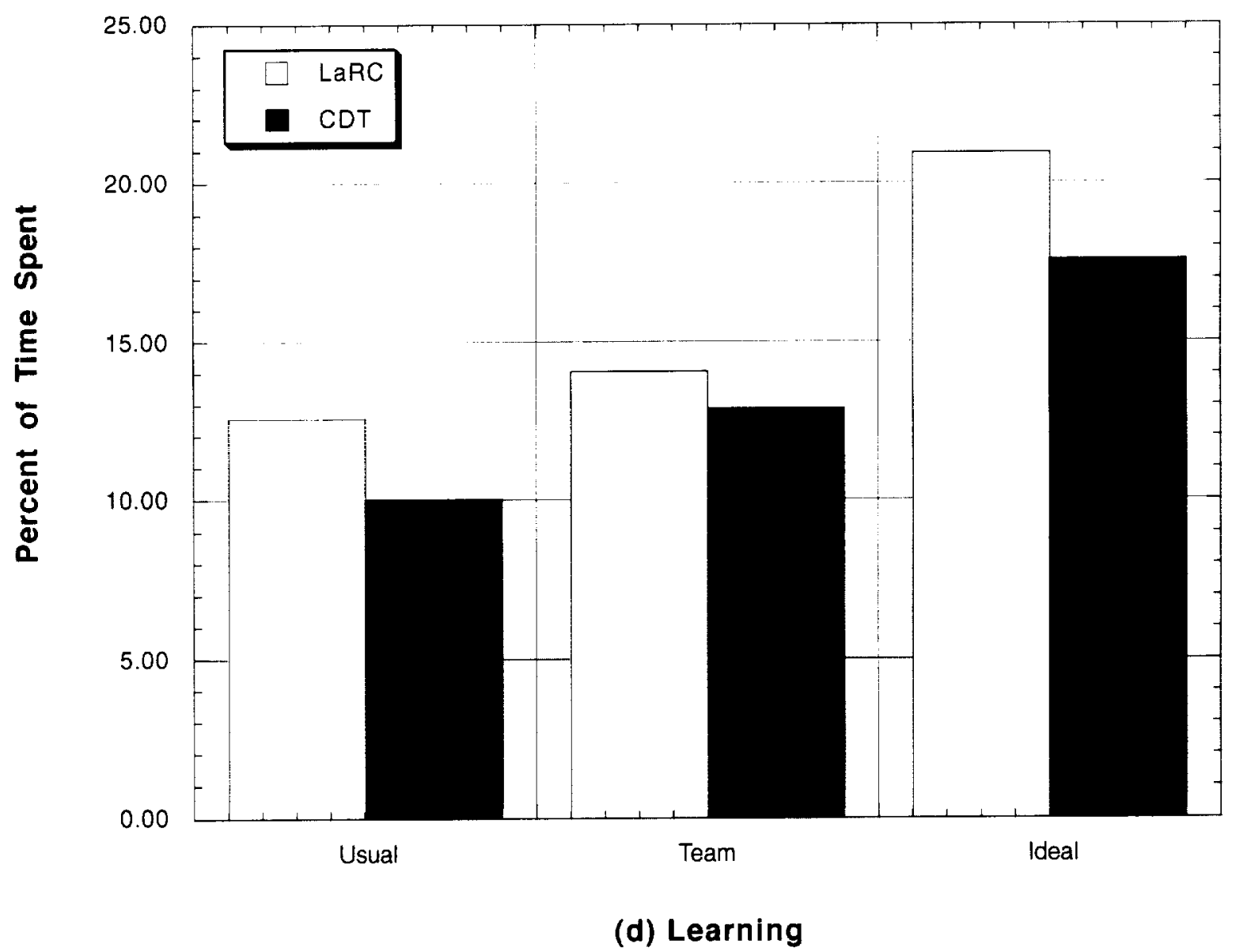

Figure 14. Continued. 


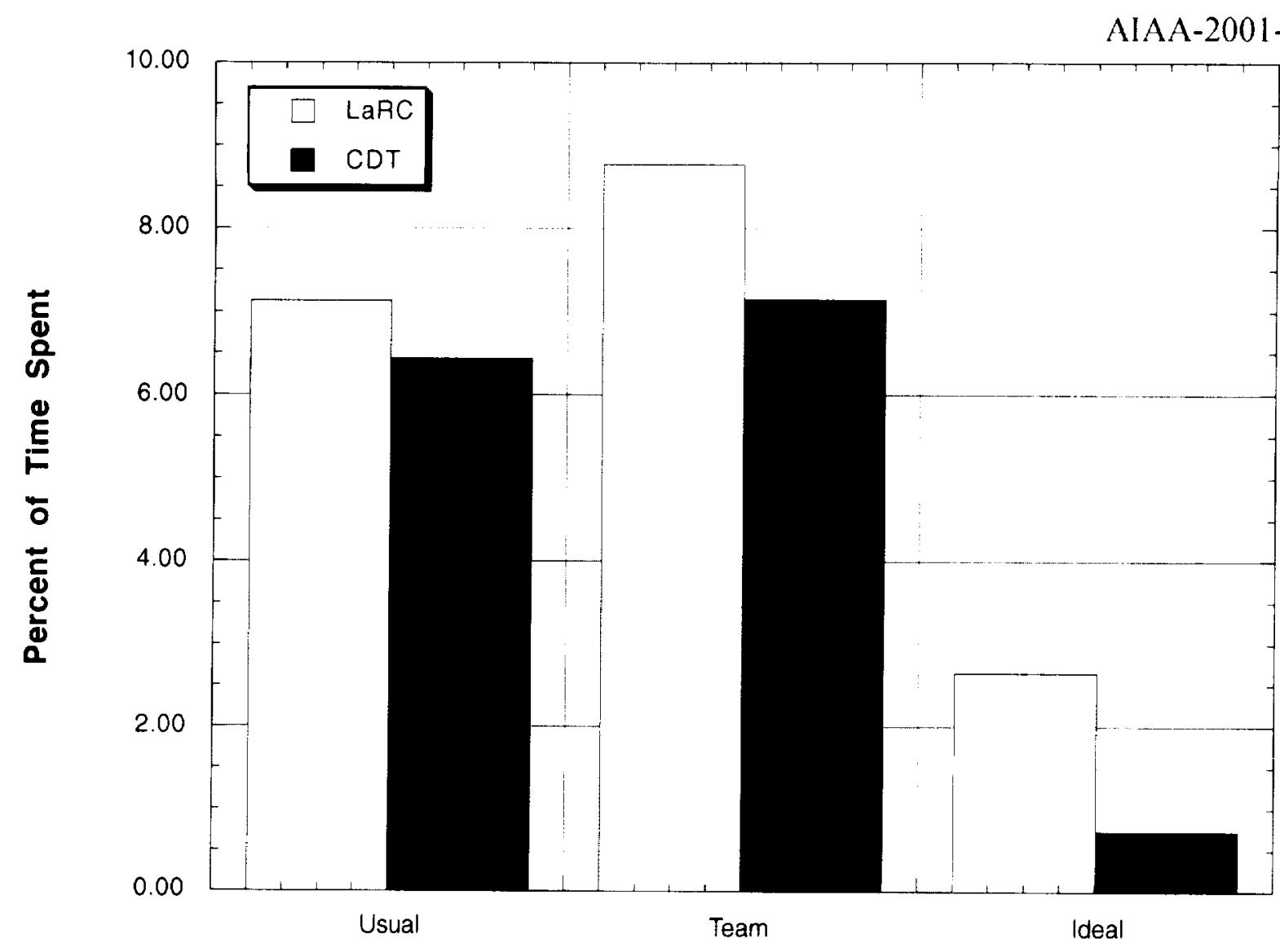

(e) Lost Time Mistakes

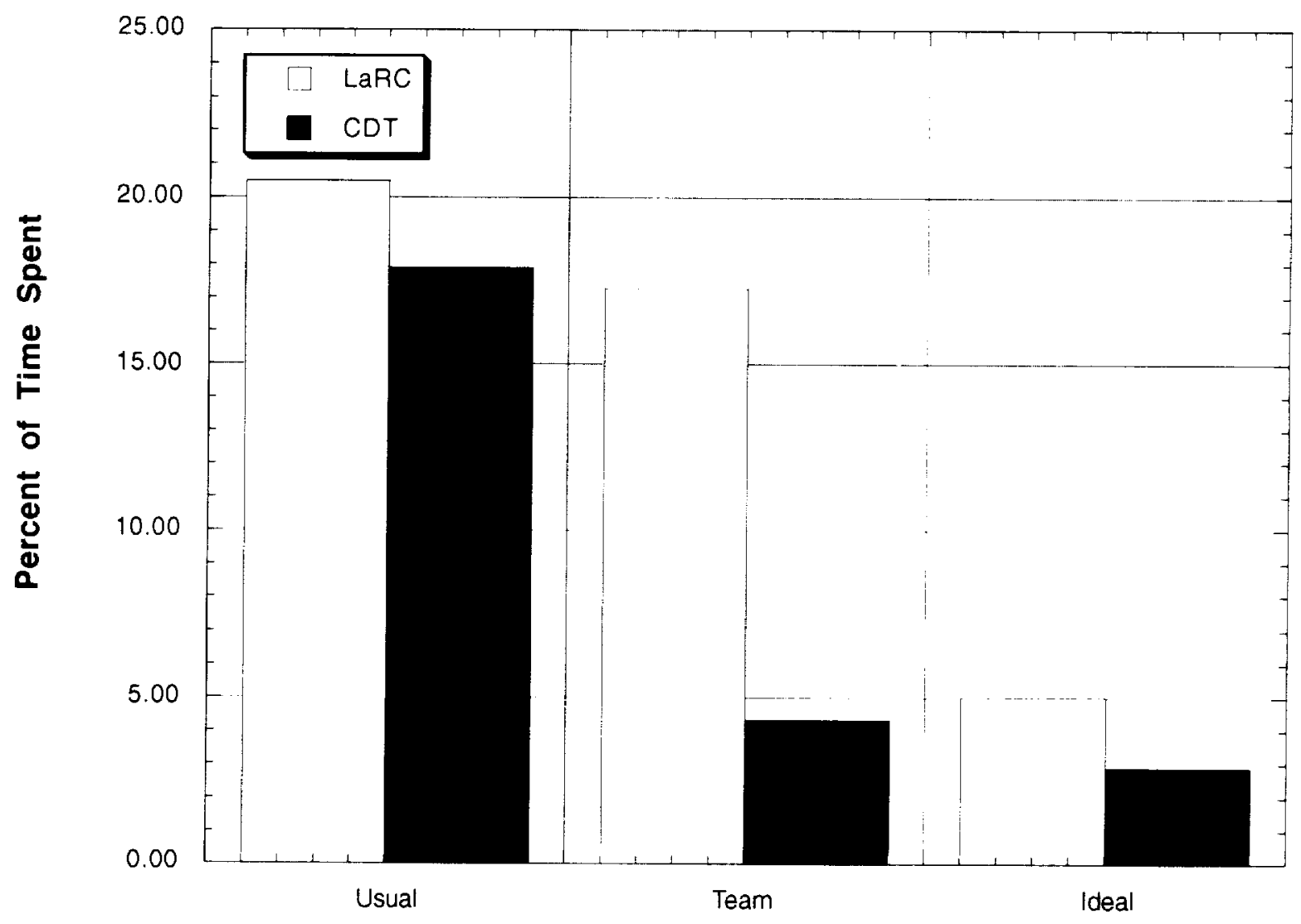

(f) Overhead

Figure 14. Concluded. 


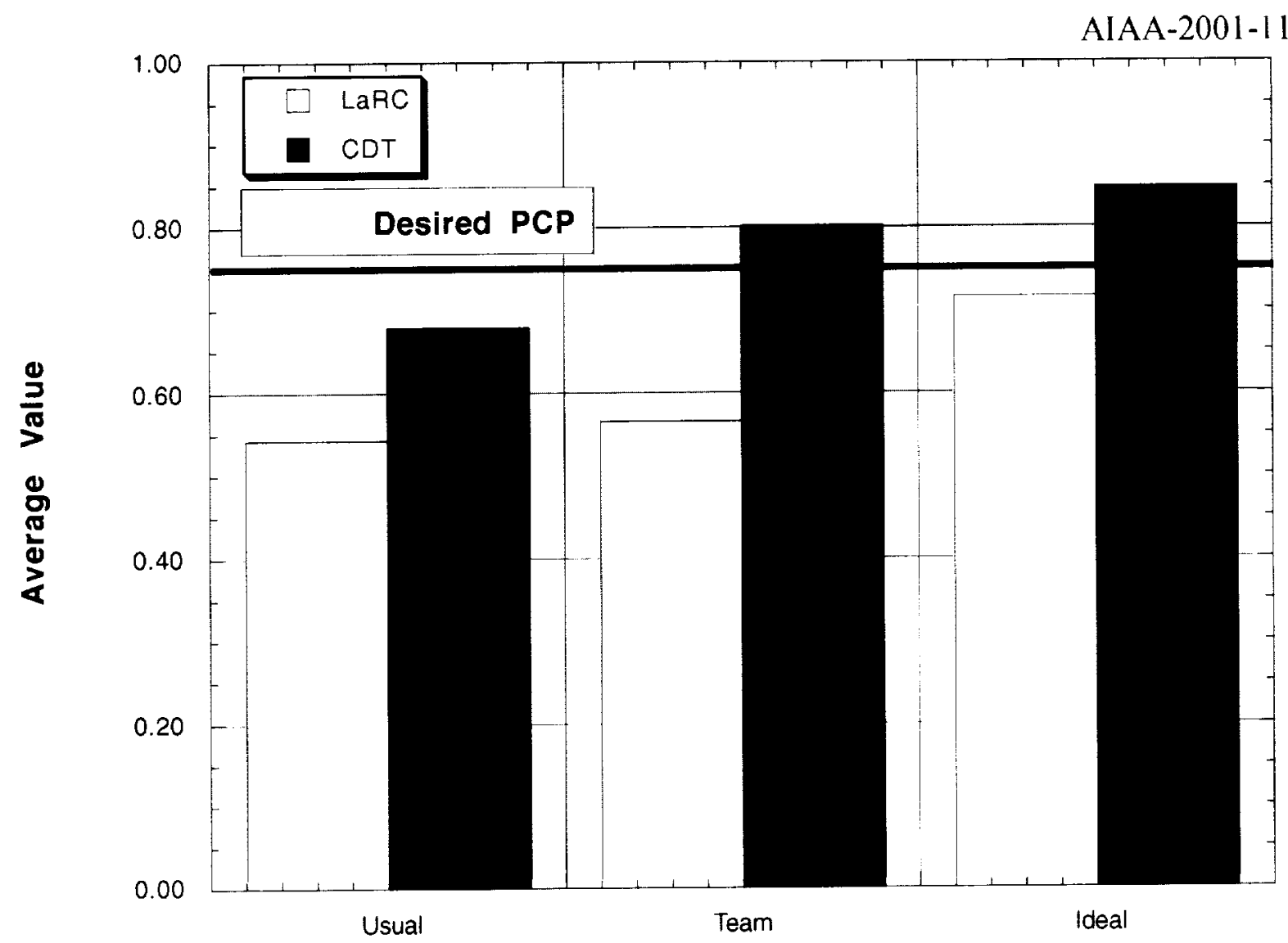

Figure 15. Personal Creative Potential (PCP) survey results.

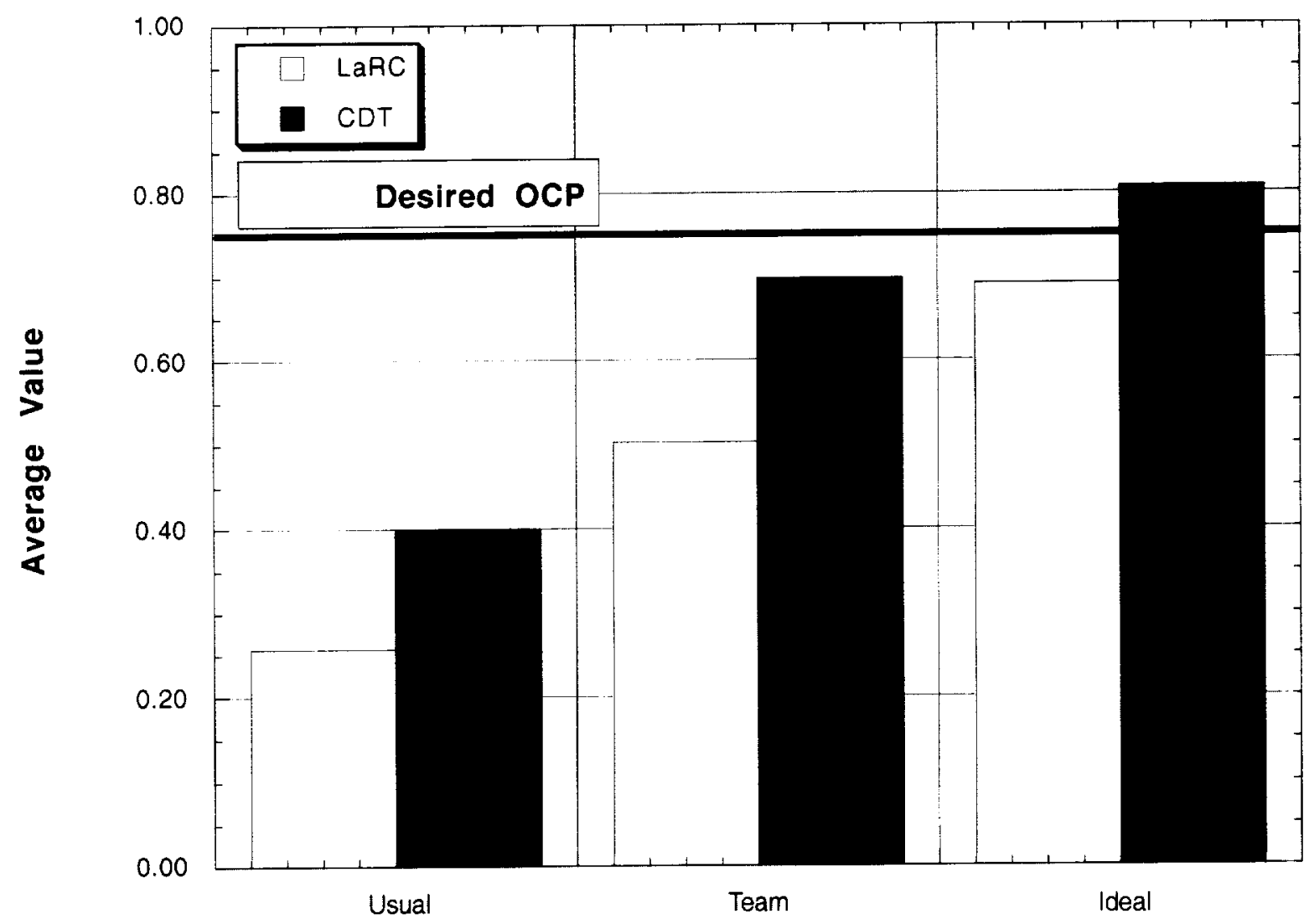

Figure 16. Organizational Creative Potential (OCP) survey results. 


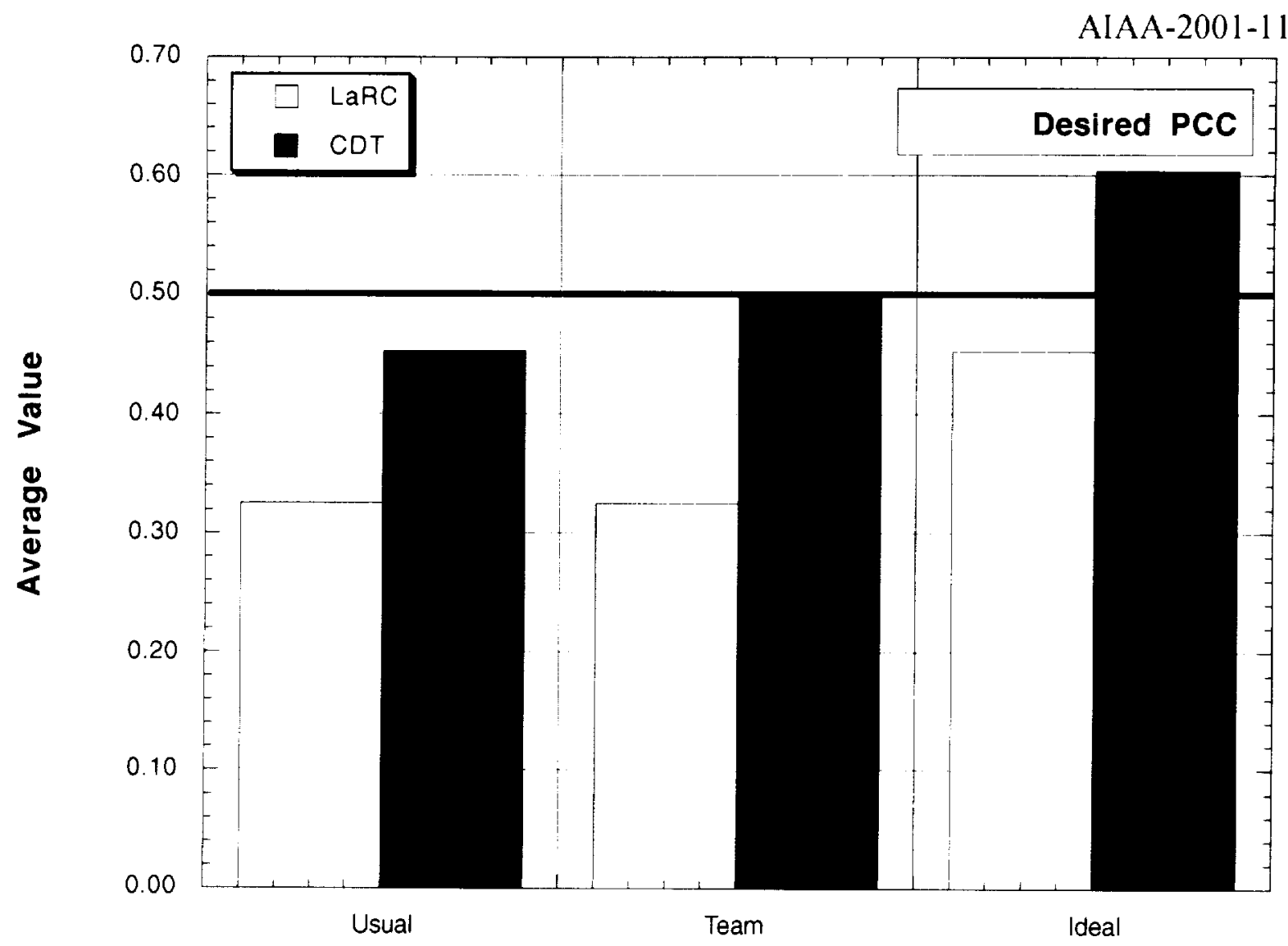

Figure 17. Personal Creative Contribution (PCC) survey results.

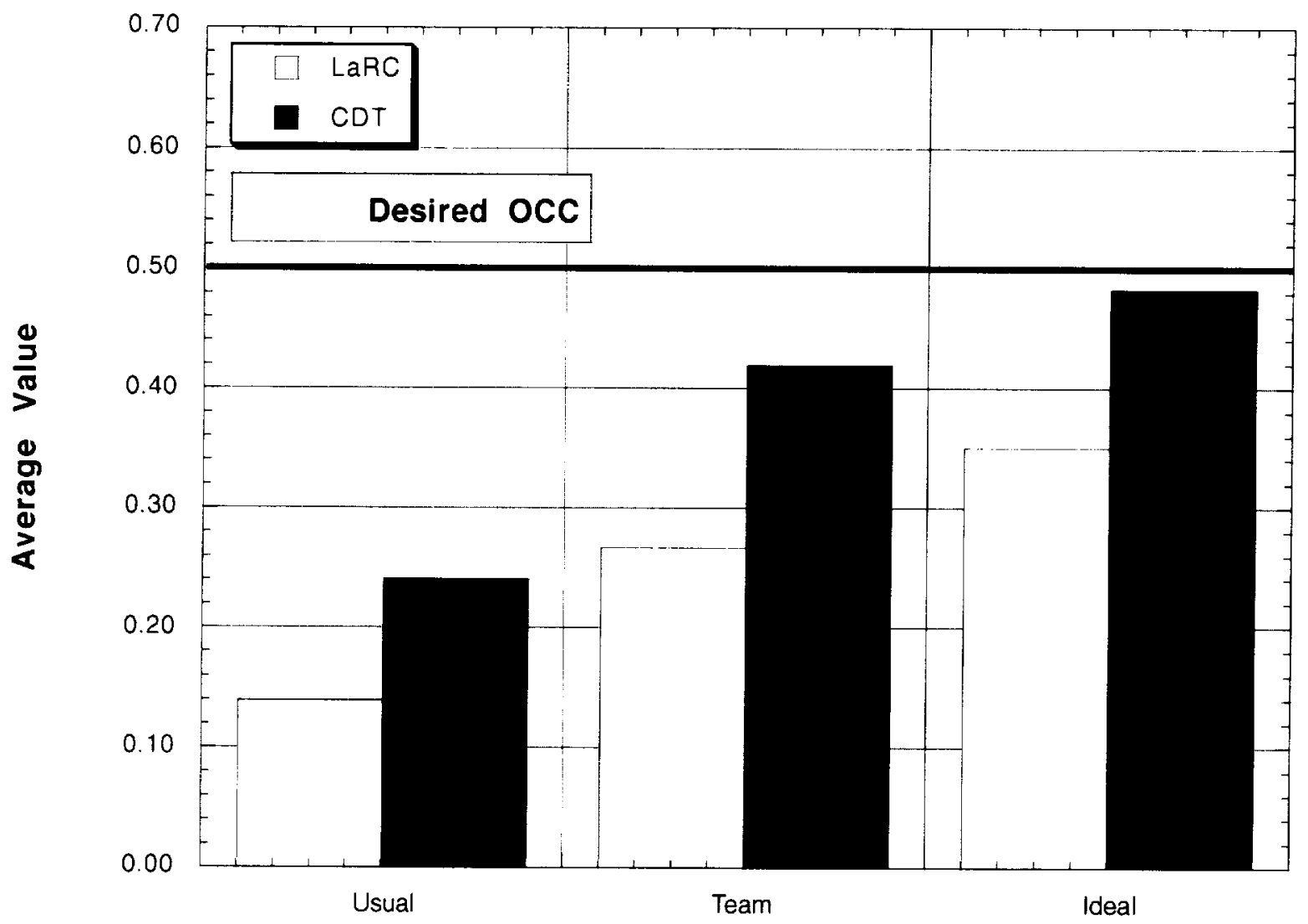

Figure 18. Organizational Creative Contribution (OCC) survey results. 
Leaders foster Inspiration to facilitate Creative work directed towards a difficult Challenge within in a shared environment governed by the criteria listed below.

- Work with $C^{4}$ goals.

- Knowledge Based decisions.
- Minimize/Eliminate program reviews.

- Minimize/Eliminate program planning.

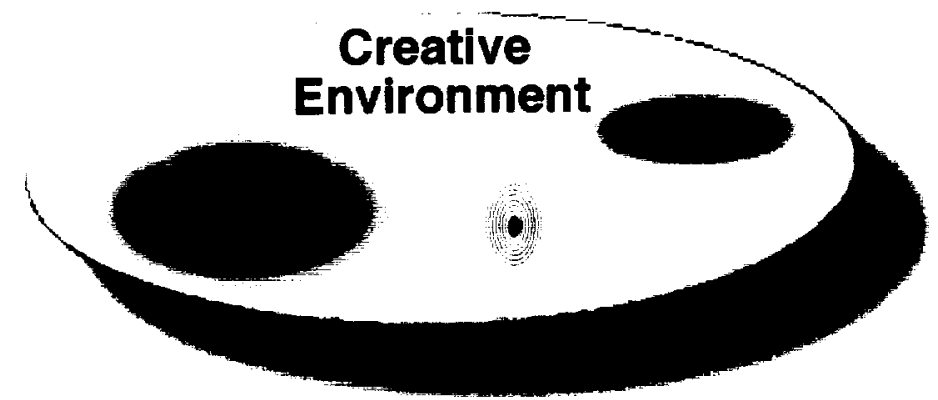

- Sunshine Policy in effect.

- Dedicated discussion spaces.

- Virtual knowledge sharing environment.

- Honor resource promises.
- All members want to enthusiastically participate.

- All members perform technical work.

- All members contributions documented.

Figure 19. Creative environment model.

\section{Creative Organization}

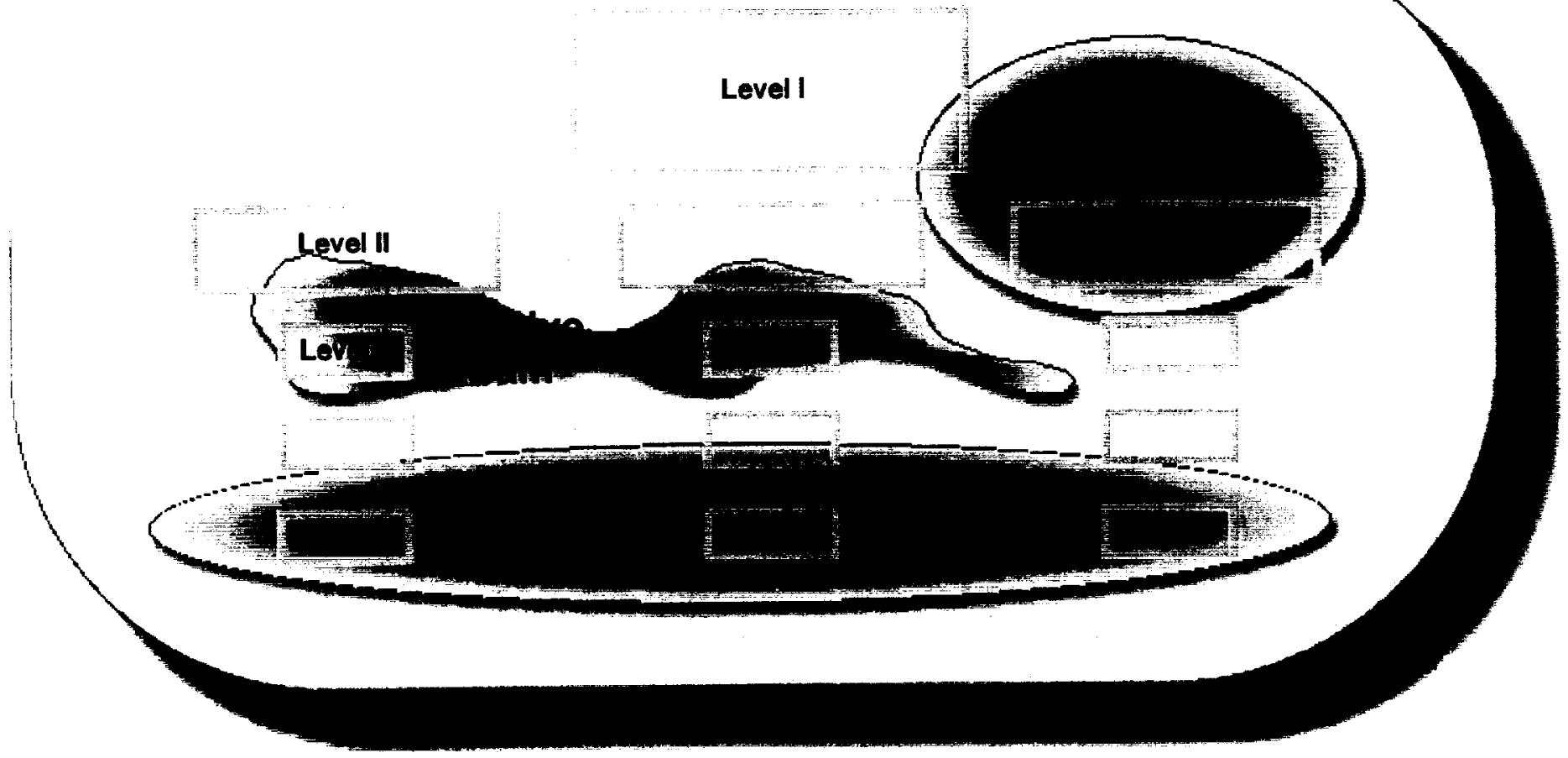

Figure 20. Creative organization model. 


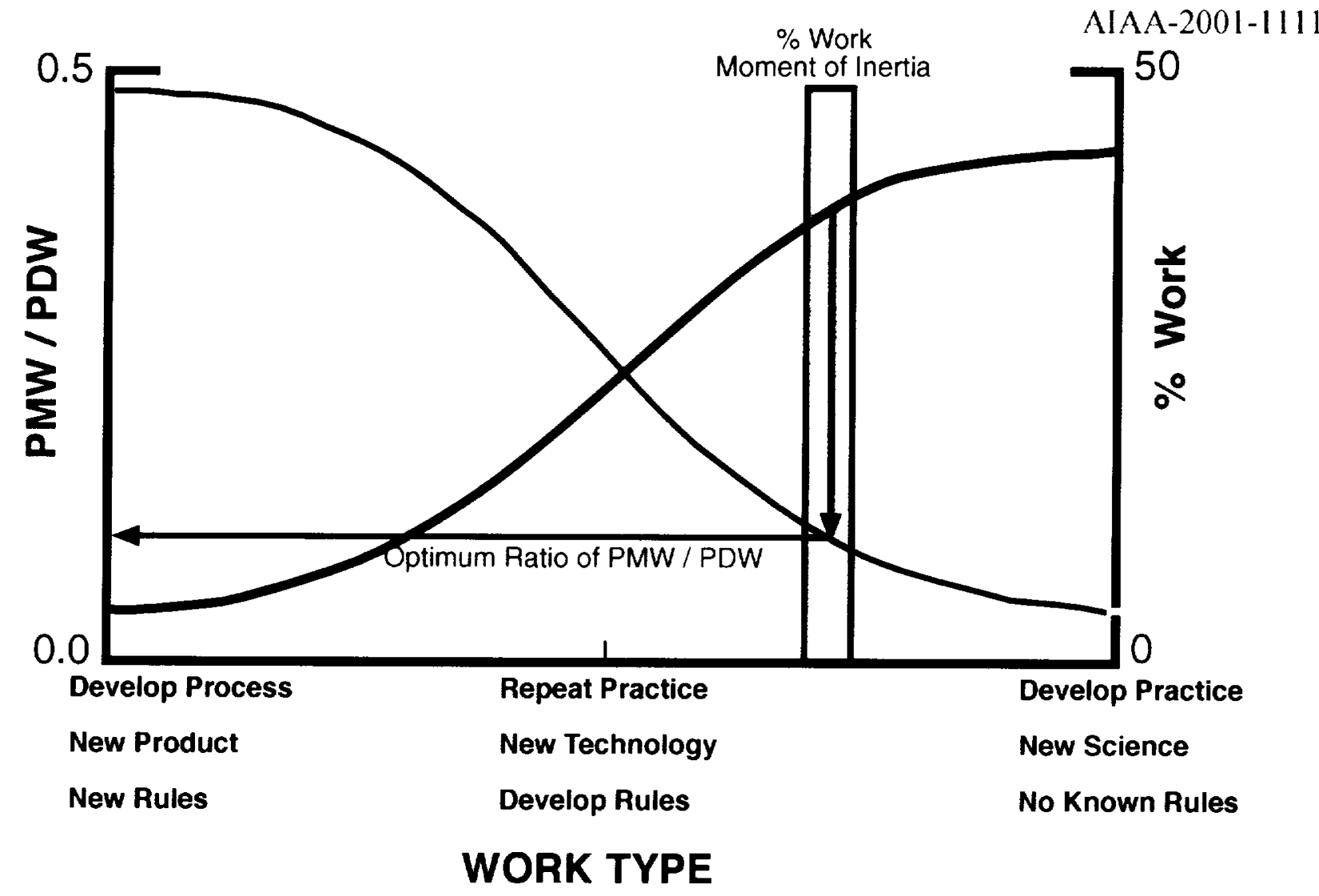

Figure 21. Creative staffing optimization.

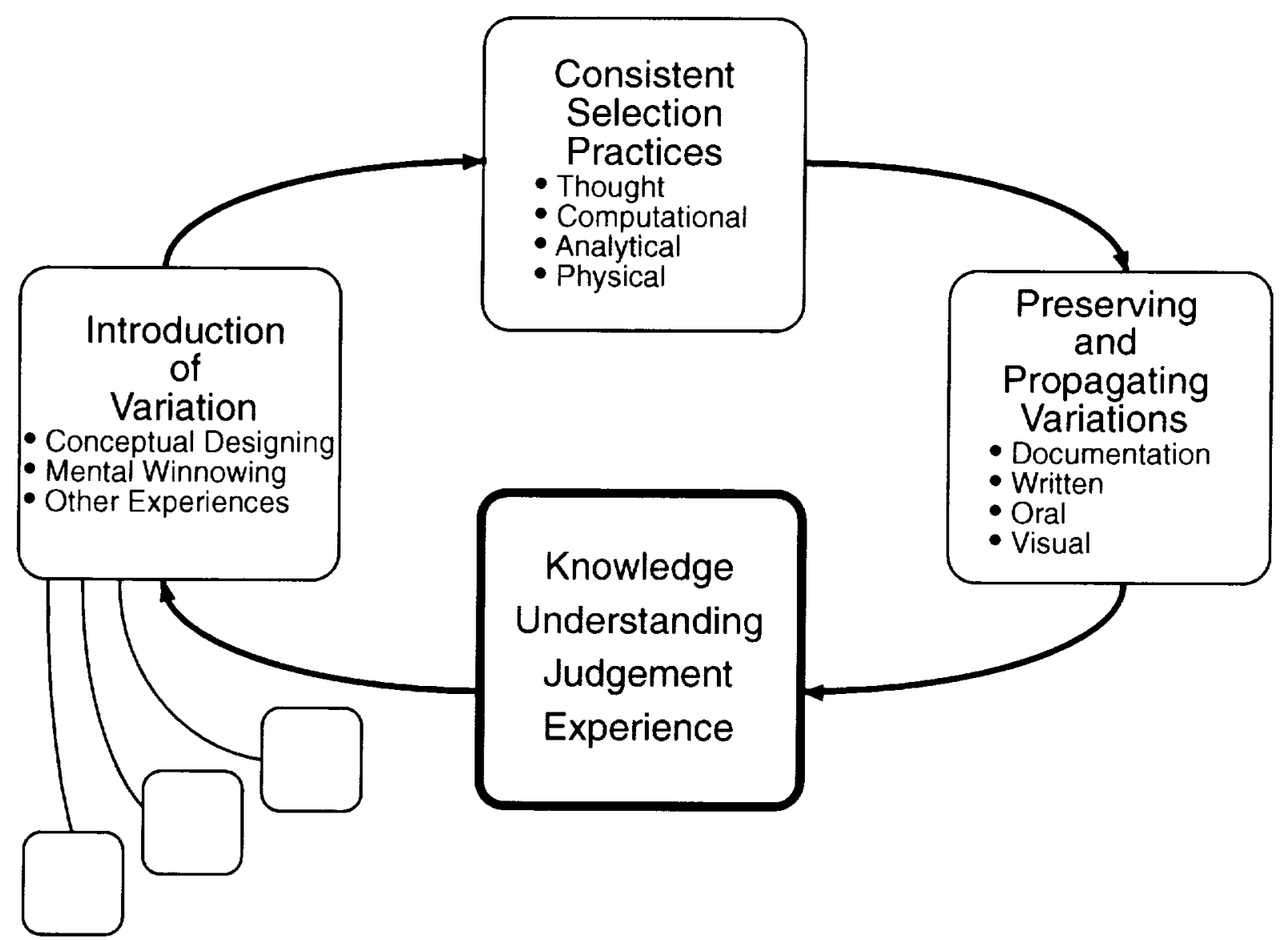

Figure 22. Knowledge growth model. 
Data has been obtained in the following 4 categories using a total of 48 questions.

- Work Elements:
(1) Type of Work (Creative, Non-Creative)
(2) Thinking
(3) Learning
(4) Overhead

- Background and Experiences:

(1) Years in Research

(2) Type of Products

(3) Number of Products

- Team Experiences:
(1) Goal Management
(2) Work Environment
(3) Member Contributions
(4) Decision Mechanisms

- Organizational Experiences:
(1) Goal Management
(2) Work Environment
(3) Acceptance of Risk
(4) Decision Mechanisms
(5) Recognition and Reward

Table 1. Survey structure. 
Please give some information about your background and experience by filling out the sections below. Estimates are fine if exact numbers are not available.

\begin{tabular}{|l|l|}
\hline Background and Experience & Number \\
\hline Years of work experience in research & \\
\hline Invention disclosures authored & \\
\hline $\begin{array}{l}\text { Scientific/Engineering documents authored (NASA papers, conference } \\
\text { papers, journal articles, books, thesis/dissertation, white papers) }\end{array}$ & \\
\hline $\begin{array}{l}\text { Experimental studies conducted (involving model prep, testing, data } \\
\text { acquisition, data reduction, data analysis) }\end{array}$ & \\
\hline $\begin{array}{l}\text { Computational studies conducted (involving geometry modeling, surface } \\
\text { and volume grid generation, code runs, data analysis) }\end{array}$ & \\
\hline $\begin{array}{l}\text { Design studies conducted (involving definition of design space, } \\
\text { development of model, analysis, selection of final design) }\end{array}$ & \\
\hline
\end{tabular}

(a) original questionaire

\begin{tabular}{|c|c|c|c|}
\hline & & $\mathrm{LiRC}$ & CDT \\
\hline \multirow[t]{4}{*}{ Years of Work Experience } & Average & 20.24 & 16.57 \\
\hline & St. Deviation & 9.64 & 5.47 \\
\hline & Minimum & 2.00 & 8.00 \\
\hline & Maximum & 41.00 & 25.00 \\
\hline \multirow[t]{4}{*}{ Invention Disclosures } & Average & 4.65 & 12.00 \\
\hline & St. Deviation & 11.32 & 17.86 \\
\hline & Minimum & 0.00 & 0.00 \\
\hline & Maximum & 40.00 & 40.00 \\
\hline \multirow{4}{*}{$\begin{array}{l}\text { Scientific/Enginecring documents } \\
\text { authored. }\end{array}$} & Average & 37.18 & 43.00 \\
\hline & St. Deviation & 23.60 & 23.13 \\
\hline & Minimum & 1.00 & 18.00 \\
\hline & Maximum & 90.00 & 80.00 \\
\hline \multirow[t]{4}{*}{ Experimental Studies Conducted } & Average & 18.00 & 14.86 \\
\hline & St. Deviation & 20.10 & 22.60 \\
\hline & Minimum & 0.00 & 0.00 \\
\hline & Maximum & 76.00 & 60.00 \\
\hline \multirow[t]{4}{*}{ Computational Studies Conducted } & Average & 18.15 & 31.43 \\
\hline & St. Deviation & 23.17 & 31.72 \\
\hline & Minimum & 0.00 & 10.00 \\
\hline & Maximum & 100.00 & 100.00 \\
\hline \multirow[t]{4}{*}{ Design Studies Conducted } & Alerage & 4.21 & 7.00 \\
\hline & St. Deviation & 6.35 & 7.72 \\
\hline & Minimum & 0.00 & 0.00 \\
\hline & Maximum & 30.00 & 22.00 \\
\hline
\end{tabular}

(b) responses

Table 2. Statistical information on the background and experiences of individual survey respondents. 
In this section of the survey, please estimate the percentage of time you spend doing each of the work elements listed below. Make this estimation for your normal work routine, for work spent during the selected team activity, and for your ideal mix.

\begin{tabular}{|c|c|c|c|}
\hline \multirow{2}{*}{ Work Elements } & \multicolumn{3}{|c|}{ Percent of time Spent } \\
\hline & $\begin{array}{l}\text { During } \\
\text { Usual } \\
\text { Work }\end{array}$ & $\begin{array}{l}\text { During } \\
\text { Team } \\
\text { Activity } \\
\end{array}$ & $\begin{array}{l}\text { Your } \\
\text { Ideal } \\
\text { Mix }\end{array}$ \\
\hline $\begin{array}{l}\text { Creative Work } \\
\text { Bring into being something new: } \\
\text { knowledge, data, concepts, or ideas. }\end{array}$ & & & \\
\hline $\begin{array}{l}\text { Non-Creative Work } \\
\text { Work that does not create something } \\
\text { new. }\end{array}$ & & & \\
\hline $\begin{array}{l}\text { Creative Thinking } \\
\text { To exercise the powers of judgement, } \\
\text { conception, and inference }\end{array}$ & & & \\
\hline $\begin{array}{l}\text { Learning } \\
\text { To gain knowledge or understanding }\end{array}$ & & & \\
\hline $\begin{array}{l}\text { Lost Time Mistakes } \\
\text { Repeating work. }\end{array}$ & & & \\
\hline $\begin{array}{l}\text { Overhead } \\
\text { Management and organizational tasks, } \\
\text { paperwork, or activities. }\end{array}$ & & & \\
\hline Total (should add up to 100 ) & & & \\
\hline
\end{tabular}

(a) original questionaire

\begin{tabular}{|c|c|c|c|c|c|c|c|}
\hline & & \multicolumn{3}{|c|}{ I.aRC } & \multicolumn{3}{|c|}{ (I)T } \\
\hline & & [sual & Team & Ideal & Isual & Team & Ideal \\
\hline \multirow{4}{*}{$\begin{array}{l}\text { Creative Work, T work effort } \\
\text { (Bring into being something new: } \\
\text { knowledge, data, concepts. or } \\
\text { ideas) }\end{array}$} & Nerage & 23.18 & $2+.76$ & 39.22 & 33.57 & 53.57 & 5500 \\
\hline & S1. Deviation & 18.20 & $19+8$ & 17.51 & 19.52 & 14.92 & 1803 \\
\hline & Mlinimum & 0.00 & 500 & 15.00 & 20.000 & +0.00 & 30.00 \\
\hline & Xlaximum & 75.00 & 75.00 & 80.00 & 7500 & 75.00 & 80.00 \\
\hline \multirow{4}{*}{$\begin{array}{l}\text { Non-Creative Work, "? work effort } \\
\text { Work that does not create } \\
\text { something new . }\end{array}$} & Sverage & 25.79 & 22.91 & 11.32 & 17.86 & $6+3$ & 5.00 \\
\hline & St Desiation & 16.91 & 17.33 & 10.02 & 10.75 & 3.78 & 7.64 \\
\hline & Minimum & 0.00 & 0.00 & 0.00 & 0.00 & 0.00 & 0.00 \\
\hline & Maximum & 7000 & 60.00 & 3000 & 35.040 & 10.00 & 2000 \\
\hline \multirow{4}{*}{$\begin{array}{l}\text { Crealive Thinking. "Work effort } \\
\text { (To exercise the powers of } \\
\text { judgement, conception. and } \\
\text { inference. }\end{array}$} & Average & 1091 & 12.26 & 20.89 & $1+29$ & 15.71 & 18.86 \\
\hline & St. Devialion & 6.06 & 795 & 7.76 & +50 & $8 \times 6$ & 584 \\
\hline & Vinimum & 0.00 & 0.00 & 0.00 & 10.00 & 500 & 10.001 \\
\hline & Maximum & 2500 & 3000 & +0.00 & 20.00 & 25.00 & 25.00 \\
\hline \multirow{4}{*}{$\begin{array}{l}\text { learning, "t work elfort } \\
\text { To gain knowledge or } \\
\text { understanding.) }\end{array}$} & Nerage & 12.53 & $1+03$ & 20.92 & 10.00 & 12.86 & 17.57 \\
\hline & St. Deviation & 853 & 1250 & 8.11 & 2.89 & 4.88 & 5.13 \\
\hline & Minimum & 5.00 & 0.00 & 1000 & 5.00 & 500 & 10.100 \\
\hline & laximum & 50.00 & 50.00 & 5000 & 1500 & 20.00 & 25.00 \\
\hline \multirow{4}{*}{$\begin{array}{l}\text { Asst Tine Mistakes, (r work effort } \\
\text { (Repeating work, }\end{array}$} & fverage & 712 & 8.76 & 2.65 & 6.43 & 7.14 & 0.71 \\
\hline & St. Deviation & 703 & 7.28 & 5.80 & 5.56 & 567 & 1.89 \\
\hline & Minimum & 0.00 & 000 & 0.00 & 0.00 & $5.00)$ & 0.00 \\
\hline & Ilaximum & 40.00 & 40.00 & 30.00 & 15.00 & 20.00 & 5.00 \\
\hline \multirow{4}{*}{$\begin{array}{l}\text { Overhead, work effort } \\
\text { (Management and organizational } \\
\text { tasks, paperwork. or activities.) }\end{array}$} & Average & $20+4$ & 17.26 & 5.00 & 17.86 & +29 & 2.86 \\
\hline & St. Deviation & 12.62 & 12.65 & 5.64 & 8.59 & 1.89 & 3.93 \\
\hline & Minimum & 000 & 0.00 & 000 & 500 & 0.00 & 0.00 \\
\hline & Maximum & 60.00 & 60.00 & 2500 & 3000 & 5.00 & 10.00 \\
\hline
\end{tabular}

(b) responses

Table 3. Statistical information on the Work Element survey. 
These criteria will be used to evaluate your organization's environment and creative potential. Please rate the criteria on a scale of 1 through 10 , where 10 indicates "strongly agree" and 1 indicates "strongly disagree". In each case, consider the criteria in the context of your work and personal experience within your organization.

\begin{tabular}{|l|l|}
\hline CREATIVE CRITERIA & $\begin{array}{c}\text { Rank 1 - 10 } \\
10=\text { STRONGLY AGREE } \\
1=\text { STRONGLY DISAGREE }\end{array}$ \\
\hline Resources available at start of research activities (CC1) & \\
\hline Intellectual freedom to solve problems (CC2) & \\
\hline Open communications (CC3) & \\
\hline Only people doing work (PDW) involved, not managers (CC4) & \\
\hline Autonomous work environment (CC5) & \\
\hline Knowledge driven decisions (CC6) & \\
\hline Simple operation requirements (CC7) & \\
\hline Simple organization requirements (CC8) & \\
\hline Goals that are concise, consistent, clear, challenging (CC9) & \\
\hline Passionate about work (CC10) & \\
\hline Flexible work approach (CC11) & \\
\hline Individual and team recognition (CC12) & \\
\hline Open to failure as well as success (CC13) & \\
\hline
\end{tabular}

(a) original questionaire

Table 4. Statistical information on the creative criteria survey questions. 


\begin{tabular}{|c|c|c|c|}
\hline Creative Criteria & & LaRC & (D) \\
\hline \multirow{4}{*}{$\begin{array}{l}\text { Resources avaialable at start of } \\
\text { research activity. }\end{array}$} & Average & 5.50 & 5.29 \\
\hline & St. Deviation & 2.48 & 3.40 \\
\hline & Minimum & 1.00 & 1.00 \\
\hline & Maximum & 10.00 & 10.00 \\
\hline \multirow{4}{*}{$\begin{array}{l}\text { Intellectual freedom to solve } \\
\text { problem. }\end{array}$} & Average & 7.79 & $7 .+3$ \\
\hline & St. Deviation & 2.01 & 1.90 \\
\hline & Minimum & 2.00 & 5.00 \\
\hline & Maximum & 10.00 & 10.00 \\
\hline \multirow[t]{4}{*}{ Open communications. } & Average & 6.97 & 6.86 \\
\hline & St. Deviation & 2.35 & 2.79 \\
\hline & Minimum & 1.00 & 1.00 \\
\hline & Maximum & 10.00 & 10.00 \\
\hline \multirow[t]{4}{*}{ Only PDW's involsed. not PMW's. } & Average & 5.71 & 6.29 \\
\hline & St. Deviation & 2.39 & 2.6 .3 \\
\hline & Minimum & 1.00 & 1.00 \\
\hline & Masimum & 10.00 & 8.00 \\
\hline \multirow[t]{4}{*}{ Autonomous work entironment. } & Average & 7.38 & 8.86 \\
\hline & St. Deviation & 2.41 & 1.07 \\
\hline & Minimum & 1.00 & 7.00 \\
\hline & Maximum & 10.00 & 10.00 \\
\hline \multirow[t]{4}{*}{ Knowledge drioven decisions. } & Alerage & 6.32 & 7.71 \\
\hline & St. Deviation & 2.18 & 1.60 \\
\hline & Minimum & 2.00 & 5.00 \\
\hline & Maximum & 10.00 & 10.00 \\
\hline \multirow[t]{4}{*}{ Simple operation requirements. } & Average & $5.4+$ & 7.14 \\
\hline & St. Deviation & 2.29 & 1.77 \\
\hline & Minimum & 1.00 & 5.00 \\
\hline & Maximum & 10.00 & 10.00 \\
\hline \multirow[t]{4}{*}{ Simple organization requirements. } & Average & 5.09 & 6.86 \\
\hline & St. Deviation & 2.39 & 1.77 \\
\hline & Minimum & 1.00 & 5.00 \\
\hline & Maximum & 10.00 & 10.00 \\
\hline \multirow{4}{*}{$\begin{array}{l}\text { Concise, consistent, clear, and } \\
\text { challenging goals. }\end{array}$} & Average & 5.76 & 6.00 \\
\hline & St. Deviation & 2.15 & 2.52 \\
\hline & Minimum & 1.00 & 1.00 \\
\hline & Maximum & 10.00 & 9.00 \\
\hline \multirow[t]{4}{*}{ Passionate about work. } & Average & 7.15 & 8.00 \\
\hline & St. Deviation & 2.39 & 2.52 \\
\hline & Minimum & 1.00 & 3.00 \\
\hline & Maximum & 10.00 & 10.00 \\
\hline \multirow[t]{4}{*}{ Flexible work appracich. } & Average & 7.32 & 8.00 \\
\hline & St. Deviation & 2.69 & 3.21 \\
\hline & Minimum & 1.00 & 1.00 \\
\hline & Maximum & 10.00 & 10.00 \\
\hline \multirow[t]{4}{*}{ Individual and team recognition. } & Average & 6.47 & 6.29 \\
\hline & St. Deviation & 2.42 & 2.75 \\
\hline & Minimum & 1.00 & 1.00 \\
\hline & Maximum & 10.00 & 9.00 \\
\hline \multirow{4}{*}{$\begin{array}{l}\text { Open to fialure as well as } \\
\text { success. }\end{array}$} & Average & 5.47 & 6.86 \\
\hline & St. Deviation & 2.31 & 2.85 \\
\hline & Minimum & 1.00 & 1.00 \\
\hline & Maximum & 10.00 & 10.00 \\
\hline
\end{tabular}

(b) responses

Table 4. Concluded. 
These criteria will be used to evaluate a selected team experience you have participated in during the last 5 years. Please rate the criteria on a scale of 1 through 10 , where 10 indicates "strongly agree" and 1 indicates "strongly disagree".

Team (optional):

\begin{tabular}{|l|l|}
\hline TEAM EXPERIENCE (TE) & $\begin{array}{c}\text { Rank 1 - 10 } \\
\text { 10=STRONGLY AGREE } \\
1=\text { STRONGLY DISAGREE }\end{array}$ \\
\hline Team goal is understood (TE1) & \\
\hline Team goal is do-able (TE2) & \\
\hline Team goal does not change (TE3) & \\
\hline Team members contribute equally (TE4) & \\
\hline Team members have opportunity for equal input (TE5) & \\
\hline Decisions are knowledge based (TE6) & \\
\hline Participation on the team is voluntary (TE7) & \\
\hline Team members decide their individual work load (TE8) & \\
\hline All information is shared continually (TE9) & \\
\hline The team is autonomous (TE10) & \\
\hline Team operations and structure are simple (TE11) & \\
\hline
\end{tabular}

(a) original questionaire

Table 5. Statistical information on the team experience survey questions. 
AIAA-2001-1111

\begin{tabular}{|c|c|c|c|}
\hline Team Experience & & LaRC & CDT \\
\hline \multirow[t]{4}{*}{ Team goal is understood. } & Average & 8.06 & 9.86 \\
\hline & St. Deviation & 2.17 & 0.38 \\
\hline & Minimum & 2.00 & 9.00 \\
\hline & Maximum & 10.00 & 10.00 \\
\hline \multirow[t]{4}{*}{ Team goal is do-able. } & Average & 7.32 & 7.14 \\
\hline & St. Deviation & 2.23 & 2.19 \\
\hline & Minimum & 2.00 & 5.00 \\
\hline & Maximum & 10.00 & 10.00 \\
\hline \multirow{4}{*}{ Team goal does not change. } & Average & $7.2+$ & 9.00 \\
\hline & St. Deviation & 2.72 & 1.29 \\
\hline & Minimum & 1.00 & 7.00 \\
\hline & Maximum & 10.00 & 10.00 \\
\hline \multirow{4}{*}{$\begin{array}{l}\text { Team members contribute } \\
\text { equally. }\end{array}$} & Average & 6.26 & 6.43 \\
\hline & St. Deviation & 2.09 & $2 .+4$ \\
\hline & Minimum & 3.00 & 3.00 \\
\hline & Maximum & 10.00 & 9.00 \\
\hline \multirow{4}{*}{$\begin{array}{l}\text { Team members have opportunity } \\
\text { for equal inpul. }\end{array}$} & Average & 7.8 .5 & 9.86 \\
\hline & St. Deviation & 2.27 & 0.38 \\
\hline & Minimum & 2.00 & 9.00 \\
\hline & Maximum & 10.00 & 10.00 \\
\hline \multirow[t]{4}{*}{ Decisions are knowledge based. } & Alerage & $7 .+1$ & $9 .+3$ \\
\hline & St. Deviation & $2 .+3$ & 0.79 \\
\hline & Minimum & 2.00 & 8.00 \\
\hline & Maximum & 10.00 & 10.00 \\
\hline \multirow{4}{*}{$\begin{array}{l}\text { Participation on the leam is } \\
\text { voluntary. }\end{array}$} & Average & 6.50 & 7.71 \\
\hline & St. Deviation & 2.98 & 2.75 \\
\hline & Minimum & 1.00 & 3.00 \\
\hline & Maximum & 10.00 & 10.00 \\
\hline \multirow{4}{*}{$\begin{array}{l}\text { Team members decide their } \\
\text { individual work loads. }\end{array}$} & Avcrage & 7.32 & 9.29 \\
\hline & St. Deviation & 2.64 & 0.76 \\
\hline & Minimum & 1.00 & 8.00 \\
\hline & Maximum & 10.00 & 10.00 \\
\hline \multirow[t]{4}{*}{ All information is shared continually . } & Average & 6.91 & $9 .+3$ \\
\hline & St. Deviation & $2.6+$ & 0.79 \\
\hline & Minimum & 1.00 & 8.00 \\
\hline & Maximum & 10.00 & 10.00 \\
\hline \multirow{4}{*}{ The team is autonomous. } & Average & 6.91 & 9.00 \\
\hline & St. Deviation & 2.81 & 0.82 \\
\hline & Minimum & 1.00 & 8.00 \\
\hline & Maximum & 10.00 & 10.00 \\
\hline \multirow{4}{*}{$\begin{array}{l}\text { Team operations and structure } \\
\text { are simple. }\end{array}$} & Average & 6.76 & 9.00 \\
\hline & St. Deviation & 2.92 & 0.82 \\
\hline & Minimum & 1.00 & 8.00 \\
\hline & Maximum & 10.00 & 10.00 \\
\hline
\end{tabular}

(b) responses

Table 5. Concluded.

32

American Institute of Aeronautics and Astronautics 


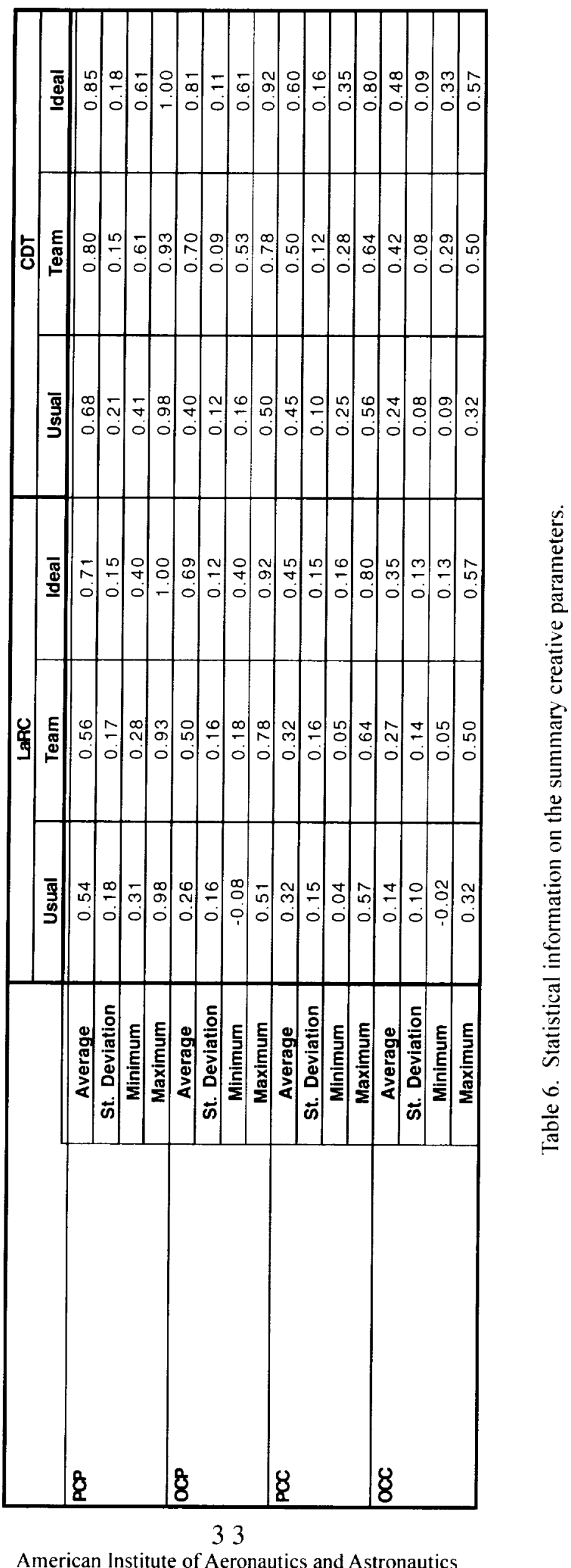

AIAA-2001-1111 
